\title{
La crisis actual a la luz de los grandes autores de la economía política
}

Robert Boyer*

\section{RESUMEN}

El retorno a la lectura de los autores clásicos hace posible una amplia interpretación de la crisis subprime. En Marx se identifica el origen de las crisis, pero también de la globalización, en las contradicciones de la acumulación, particularmente la financiera. Keynes, y después Minsky, contribuyen a valorar la función de las finanzas en la determinación del empleo y las inestabilidades macroeconómicas. Wicksell destaca la función de las tasas de interés en la génesis de las fases de expansión y de impulso; mientras que el modelo de Von Neumann permite detectar las burbujas especulativas en Internet y el mercado inmobiliario estadounidense. A su vez, Schumpeter vincula innovación y acceso al crédito como la fuente de las fases de expansión, y posteriomente del vuelco drástico de la coyuntura. Para Fisher, la reabsorción del exceso de endeudamiento que conduce a la crisis puede desembocar en una depresión asociada con una deflación. Estos fenómenos, en el caso de la crisis iniciada en septiembre de 2008, proveen una interpretación caleidoscópica y, finalmente, ésta sería más hayekiana que keynesiana.

Palabras clave: crisis financiera, crisis de la subprime, historia del pensamiento, Marx, Keynes, Fisher, Wicksell, Hayek, Von Neumann.

Clasificación JEL: E11, E12, E13, E44, G28.

\section{Abstract}

The return to classical authors allows a wide explanation of the subprimes crises. By reading Marx we identify not only the crisis origin but also the globalization one by means of accumulation contradictions, particularly financial. With Keynes and after Minsky is possible to value finances role on employment level and macroeconomic instabilities. Wicksell helps to understand the role of speculative burbles on Internet and the American real state market. Meanwhile, Schumpeter links innovation and access to loan as the source of expansion and after the overturn of the economic situation. To Fisher, curbing bank Indebtedness excess that leads to crisis could become into depression link to a deflation. This phenomenon in the case of the crisis of September 2008, provide a kaleidoscope explanation and it would be more Hayekian than Keynesian.

Key words: financial crisis, subprime loan crisis, historical economic though, Marx, Keynes, Fisher, Wicksell, Hayek, Von Neumann

Classification JEL: E11, E12, E13, E44, G28.

* Profesor y director de estudios en l'EHESS de París. Coorganizador del programa de doctorado en economía institucional (1997-2001). Es miembro del Consejo Científico del Centro de SaintGobain de Estudios Económicos. Fue presidente de la Asociacion de Investigación y Regulación, y miembro del Consejo de Análisis Económico en Francia. Traducción del francés de Vania Galindo Juárez. 


\section{INTRODUCCIÓN}

La crisis contemporánea también es la crisis del paradigma económico dominante de las dos décadas pasadas. Su pérdida de credibilidad es, desde luego, mucho menos dramática que las consecuencias económicas y sociales de la recesión de 2008-2009, pero la ausencia de una construcción alternativa pone en peligro las posibilidades de encontrar una salida a la crisis. En efecto, si la configuración anterior persiste en el campo de las teorías económicas estándar, entonces se incrementa la probabilidad de que las estrategias que estas teorías sugieren nos conduzcan a la repetición de una crisis de la misma índole, aunque aún más grave, debido a que se acumularían nuevos desequilibrios asociados con una reactivación del crédito, ya no privado, sino esencialmente público.

Por consiguiente, resulta fundamental producir un paradigma que permita la inteligibilidad de la crisis contemporánea. En este marco se presentan dos estrategias de investigación:

- Por un lado, resulta evidente que la voluntad de construir una economía totalmente separada de las demás ciencias sociales -con excepción de la exportación de sus herramientas de análisis o de sus métodos- erosionó la pertinencia del análisis de los investigadores contemporáneos. Un primer programa de investigación consiste, entonces, en hacer una recomposición de las ciencias sociales (Orléan, 2009) o, cuando menos, en tomar en cuenta las interdependencias multiformes entre las diversas esferas de las sociedades contemporáneas (Kessler, 2009). Por ejemplo, el resurgimiento de la noción de "espíritus animales" se puede interpretar como un desplazamiento de la economía hacia la psicología o las ciencias cognitivas (Akerlof y Shiller, 2009), que la propia prensa financiera parece adoptar (Plender, 2009).

- Por otro lado, muchas preocupaciones, nociones e intuiciones de la economía política han sido olvidadas por la profesión de los economistas, debido a la presión de la especialización por una estructuración institucional del ámbito académico. De este modo, el triunfo de los análisis en términos de equilibrio se alejó en gran medida de la comprensión de los procesos dinámicos que conducen a las crisis, aunque no solamente a causa del placer estético que experimentan los economistas respecto a los modelos elegantes, pero completamente irreales (Krugman, 2009). El segundo proyecto consiste, entonces, en una renovación de la econo- 
mía política a la luz de la evolución que ha tenido el capitalismo desde esa época, y en las múltiples herramientas de análisis que pueden movilizar a los investigadores contemporáneos.

El presente artículo está dedicado, precisamente, a este segundo proyecto.

\section{LOS OLVIDOS Y ERRORES DE LAS TEORÍAS ESTÁNDAR}

En primer lugar, los investigadores contemporáneos se complacen en creer que los artículos publicados en el transcurso de los cinco años pasados incorporan y totalizan el conjunto de los conocimientos de la economía política y del análisis económico recientemente convertido en la ciencia económica. En realidad, esto no es así, pues la crisis hace que resurja la pertinencia de teorías y de autores que, desde hace mucho, se habían suprimido de casi todos los planes de estudio de los economistas. Sus nombres son Karl Marx, Knut Wicksell, Irving Fisher, Frank Knight, Joseph Schumpeter, John-Maynard Keynes y Hyman Minsky. Sin embargo, cada uno de ellos provee un análisis esclarecedor de una u otra de las características de la crisis contemporánea, ya que todos tienen en común el hecho de hacer explícitas algunas de las relaciones centrales entre moneda, crédito, finanzas y nivel de actividad.

La segunda debilidad de la teoría estándar se refiere a la centralidad del concepto de equilibrio, el cual tiende a abolir el tiempo histórico para sólo considerar, en el mejor de los casos, un tiempo cinemático, el de la convergencia hacia un equilibrio estático en un ambiente estacionario. Efectivamente, el éxito de su programa de investigación provino de la fortaleza de sus tres hipótesis fundacionales. Una racionalidad sustancial permite a cualquier agente calcular las consecuencias de sus elecciones con tan sólo algunos factores estocásticos de diferencia. Estos últimos interactúan a partir de una serie de mercados, con exclusión de cualquier otro procedimiento de coordinación: el sistema de precios relativos que se obtiene de esta forma constituye la única información pertinente. La moneda es accesoria, ya que no hace sino convertir los precios relativos en precios expresados en una unidad de cuenta común. Entonces, un choque monetario sólo tiene efectos transitorios, de tal manera que la moneda es neutral. Finalmente, cuando el análisis se extiende a un modelo que incorpora diversos periodos, el teórico dota a los agentes de la capacidad de anticipar perfectamente los estados futuros de la economía, con excepción, nuevamente, de los choques exógenos, denominados aleatorios. Por tanto, pueden existir ciclos, pero éstos se manifiestan 
mediante la evolución de un equilibrio, sin que los agentes tengan jamás la experiencia de una secuencia de ajuste sobre los mercados, los cuales ya no se ajustan por los precios, sino por el racionamiento.

La tercera limitante es más perniciosa, pues se presenta enmascarada. No cabe duda de que el último medio siglo se caracterizó por una explosión sin precedentes de la división del trabajo; es decir, de la especialización de las investigaciones en economía, según diversos subparadigmas y en función de ámbitos cada vez más divididos y compartimentados. La explosión del número de revisiones al campo (cada vez más estrecho) y, por oposición, el declive de las obras como medio de comunicación entre economistas, dan cuenta de esta balcanización de la profesión. Actualmente, resulta muy discutible que los resultados obtenidos bajo estos preceptos definan una ciencia coherente, ya que las hipótesis precisas adoptadas en uno u otro campo pueden estar en las antípodas, y los postulados de base pueden ser contradictorios o, en el mejor de los casos, no tener relación con el corpus central de la economía.

Este último factor se relaciona particularmente con la especialización de los ámbitos de investigación propios de las finanzas. La economía financiera de mercado se constituyó gracias a una ruptura casi radical con los análisis anteriores de los economistas, concernientes a las relaciones entre financiamiento y macroeconomía.

Por profesión, los diseñadores de los productos derivados se centraban en las características de un producto financiero muy particular, sin cuestionarse casi nunca acerca de las condiciones macroeconómicas que legitimaban su cálculo, ni respecto de las consecuencias que tienen estos productos derivados en la estabilidad financiera y en las evoluciones macroeconómicas, dado que éstos se difunden al conjunto de la sociedad y pueden transformar progresivamente el modo de regulación.

De manera recíproca, tras la victoria de la teoría de los ciclos reales los modelos macroeconómicos canónicos no incorporaron el funcionamiento del sector financiero; por tanto, por construcción, no tenían la capacidad de anticipar la crisis financiera que estalló en septiembre de 2008 ni mucho menos de proponer los medios para superarla.

De este modo, se explica el estupor de la mayoría de los analistas, para quienes los acontecimientos que se encadenaron desde el vuelco en la tendencia del mercado inmobiliario estadounidense y, aún más, tras la quiebra de Lehman Brothers, se presentaron como acontecimientos sorpresivos y excepcionales que algunos tienden a equiparar con una catástrofe natural. La gravedad de la crisis 
iniciada en 2008 invita a un New Deal de las teorías financieras y, aún más, de la macroeconomía, la cual hoy en día se ha convertido en digna de un moderno Doctor Pangloss. En el cuento de Voltaire, este último consideraba -frente a las peores injusticias y catástrofes- que "todo sucede para bien en éste, el mejor de los mundos posibles". Los fundamentalistas del mercado consideran que, efectivamente, sea cual sea el resultado de una pura lógica mercantil, ésta conduce al mejor de los equilibrios económicos posibles. Esto es hacer un uso abusivo de los dos teoremas de la economía del bienestar, los cuales postulan, primero, que todo equilibrio de mercado es un óptimo y, después, y sobre todo, que todo óptimo puede ser alcanzado por un equilibrio de mercado. Estos fundamentalistas olvidan, despreocupadamente, que este maravilloso resultado, que es la base de la creencia en la mano invisible de Adam Smith, sólo está respaldado si prevalecen siete hipótesis (Arrow, Debreu, 1954; Debreu, 1954), pero en realidad todas ellas se violan en las economías específicas (Hollingsworth, Boyer, 1997). El abuso de autoridad se hace aún más evidente cuando se extiende a los mercados financieros, los cuales, por definición, introducen una incertidumbre radical que los pocos mercados de derivados existentes no logran enmarcar.

Así, lo que conviene reexaminar son las bases mismas de la macroeconomía, gracias a que se toma en cuenta de manera explícita el papel de la moneda y de las finanzas, el análisis de los procesos temporales de ajuste, en particular los desequilibrios de la acumulación, y la introducción de un concepto de crisis distinto de la fase recesiva de un ciclo económico tradicional, que a su vez es endógeno.

\section{EL MERCADO PRESUPONE LA MONEDA QUE HACE POSIBLES LAS CRISIS}

En los modelos de equilibrio general, la existencia de un sistema de precios que asegure la compatibilidad del conjunto de transacciones elimina de tajo la posibilidad de una crisis. Sin embargo, sucede que, lejos de representar el proceso del intercambio mercantil, estos modelos suponen, de hecho, una planeación central en la que los bienes se intercambian por bienes (Benassy, 1984). Todas las transacciones se realizan en el transcurso de un solo periodo, de manera que la moneda es una simple unidad de cuenta cuyo stock se desvanece una vez que los intercambios han sido realizados, ya que ésta no tiene valor intrínseco. De cierta forma, la extensión a toda la economía es una fábula que haría del trueque la relación económica fundamental, de la moneda un simple velo y de una crisis una imposibilidad lógica. 
De hecho, las investigaciones contemporáneas, institucionalistas e históricas, demuestran de manera convincente que el mercado deriva de la existencia y de la aceptabilidad de la moneda como intermediario necesario de los intercambios fundamentalmente descentralizados (Aglietta y Orléan, 1998 y 2002). $\mathrm{Su}$ introducción tiene dos efectos en la economía. Por un lado, la reducción de los costos de transacción estimula los intercambios que, a su vez, permiten la división del trabajo y la especialización. A partir de Adam Smith, muchos han coincidido en que éste es el origen del crecimiento (Kaldor, 1966). Sin embargo, por otro lado, la separación del acto de compra del acto de venta, gracias a la moneda, introduce una incertidumbre en cuanto a la correspondencia automática de la oferta y la demanda. A priori, el productor debe anticipar la demanda que le será destinada y su pronóstico puede resultar inválido, dado que la economía no es estacionaria. De este modo, se abre la posibilidad de las crisis económicas como característica inherente a una economía mercantil, en contraste con los regímenes económicos anteriores en los cuales estas crisis más bien provenían de choques denominados exógenos (malas cosechas, guerras, etcétera).

\section{MARX, TEÓRICO DE LAS CRISIS, ANALISTA DEL CAPITAL FICTICIO, DE LA ACUMULACIÓN Y DE LA MUNDIALIZACIÓN}

Como lo demostró hace ya mucho tiempo Marx en El capital (1867), la existencia de la moneda provoca una sacudida en las razones que llevan al intercambio mercantil. Si bien en un inicio ésta favorece el incremento del bienestar, gracias al intercambio de valores de uso, también permite que emerja una lógica totalmente distinta, a saber, la producción con miras al valor de cambio.

\section{Las crisis inherentes a una economía monetaria}

Para el intermediario, que es el comerciante, como más adelante lo sería para el empresario capitalista, los intercambios y la producción no son más que etapas intermedias en la valorización de su capital: su obsesión se convierte en acumular bajo la forma monetaria. La flexibilidad de la respuesta de la oferta de mercancías tiene como contraparte una mayor probabilidad de desconexión respecto a la demanda. Así, aparecen las crisis mercantiles y luego las industriales como características endógenas de un sistema económico, y ya no más como una perturbación exterior y aparentemente exógena. La historia económica confirma que a las crisis de escasez de la regulación a la manera antigua, puestas en evidencia 
por la Escuela de los Anales, les siguieron las crisis de sobreproducción de la regulación competitiva de la primera etapa del capitalismo industrial, analizada por Marx (Boyer y Coriat, 1985).

\section{La permanencia de encadenamientos tipo que conducen a las crisis, incluidas las más contemporáneas}

A pesar de que Marx se sitúa en el ámbito de las crisis financieras bajo regulación competitiva, para poder retomar la clasificación de las investigaciones regulacionistas (Aglietta, 1978; Boyer 1986; Lipietz, 1983; Boyer y Saillard, 1995), este autor nos provee una impresionante descripción de los encadenamientos que tienen lugar tras el estallido de una ola de especulación:

En un sistema de producción, cuya coherencia esté enteramente basada en el crédito, debe surgir inevitablemente una crisis y una demanda violenta de medios de pago cuando se suprime bruscamente el crédito y sólo son admitidos los pagos en efectivo. A primera vista, todo debe reducirse a una crisis de crédito y de dinero, siendo que sólo es cuestión de tener la posibilidad de convertir letras de cambio en dinero. Sin embargo, estas letras de cambio representan, por una parte $-\mathrm{y}$ es la gran mayoría-, ventas y compras reales que rebasan por mucho las necesidades de la sociedad y, por esto mismo, son las causas de la crisis; por otra parte, representan negocios turbios que sólo entonces salen a la luz, especulaciones desafortunadas hechas con el capital de otros y mercancías depreciadas e invendibles. En estas circunstancias, el sistema artificial al que desemboca la expansión violenta del proceso de reproducción naturalmente no puede volverse normal mediante la intervención de un banco, por ejemplo, el Banco de Inglaterra, el cual usaría su papel para facilitar a los usureros el capital que les hace falta y comprar a su primer valor nominal todas las mercancías depreciadas. De hecho, todo parece estar al revés en este mundo del papel, en el que no hay lugar para que se crucen los precios reales con su momento real y en el que siempre es cuestión de lingotes, monedas, billetes, letras de cambio y valores; principalmente en los centros, como Londres, donde se concentran todos los asuntos financieros del país (sección V, cap. XXVII).*

Si las letras de cambio se reemplazan por los productos derivados y los títulos, lo que destaca es una notable invariabilidad del perfil de las crisis financieras,

* La traducción se realizó a partir de la cita en francés que aparece en el texto original, al igual que otras citas semejantes. (N. del T.) 
incluso más allá de las profundas diferencias entre el capitalismo competitivo y el capitalismo dominado por los mercados financieros. En primer lugar, se reconoce la carrera por la liquidez que marcaron el otoño y el invierno de 2008-2009, a pesar de que en esta ocasión ya no se trató del acceso al dinero, sino del acceso a la liquidez de la Banca Central y, por supuesto, esto significa un cambio considerable, ya que pone en duda la legitimidad de su acción (Touffut, 2008). En segundo lugar, el carácter ficticio de las evaluaciones anteriores salta a la vista, ante la gran sorpresa de los dealers y los inventores de productos derivados. A partir de la época de Marx, el estallido de la especulación pone al descubierto una gran cantidad de negocios turbios que, lejos de ser la causa, no son sino los síntomas de la entrada a la crisis: el colapso del fondo Madoff forma parte del proceso mismo de las crisis financieras. La última parte de la cita es incluso cruel para los secretarios del Tesoro estadounidenses contemporáneos, quienes parecen haber mantenido durante demasiado tiempo la ilusión de lograr una salida de la crisis mediante la simple readquisición del conjunto de productos tóxicos, sin mayor menoscabo respecto al precio nominal. Por último, basta reemplazar Londres por Nueva York para que cobre sentido otra de las intuiciones de Marx, a saber, la tendencia a la concentración de las finanzas en uno o varios lugares particulares en cada época. Si bien para los economistas ortodoxos Marx es el ejemplo del error en economía, es necesario dejar constancia de que el análisis de las crisis financieras de Marx es, por mucho, superior al suyo.

\section{El crédito precipita las crisis que reactivan la transformación de las formas de organización}

En el tomo III de El capital, Marx desarrolla el siguiente análisis:

Si el sistema crediticio aparece como palanca principal de la sobreproducción y de la superespeculación en el comercio, ello sólo ocurre porque en este caso se fuerza hasta su límite extremo el proceso de la reproducción, elástico por su naturaleza, y porque se lo fuerza a causa de que una gran parte del capital social resulta empleado por los no propietarios del mismo, quienes en consecuencia ponen manos a la obra de una manera totalmente diferente a como lo hace el propietario que evalúa temerosamente los límites de su capital privado, en la medida en que actúa personalmente. De esto sólo se desprende que la valorización del capital fundada en el carácter antagónico de la producción capitalista no permite el libre y real desarrollo más que hasta cierto punto, es decir, que de 
hecho configura una traba y una barrera inmanentes de la producción, constantemente quebrantadas por el sistema crediticio. Por ello, el sistema de crédito acelera el desarrollo material de las fuerzas productivas y el establecimiento del mercado mundial, cuya instauración hasta cierto nivel en cuanto a fundamentos materiales de la nueva forma de producción constituye la misión histórica del modo capitalista de producción. Al mismo tiempo, el crédito acelera los estallidos violentos de esta contradicción, las crisis, y con ello los elementos de disolución del antiguo modo de producción (sección V, cap. XXVII, pp. 568-569).

Otra cita más explica la crisis actual:

Las características bifacéticas inmanentes al sistema crediticio -que por una parte es fuerza impulsora de la producción capitalista, del enriquecimiento por explotación de trabajo ajeno, hasta convertirlo en el más puro y colosal sistema de juego y fraude, restringiendo cada vez más el número de los pocos individuos que explotan la riqueza social, mientras que por la otra constituye la forma de transición hacia un nuevo modo de producción- es una ambigüedad tal que confiere a los principales pregoneros del crédito, desde Law hasta Isaac Pereire, su agradable carácter híbrido de timadores y profetas (sección V, cap. XXVII, p. 569).

A la luz de esta problemática, resulta imposible regresar a la configuración de principios de la década de 2000, pues la crisis reveló desequilibrios estructurales de tal magnitud que el desafío de esta década, y probablemente de la siguiente, no es más que la reconfiguración de un orden internacional viable, la redefinición de las relaciones entre lo político, lo financiero y lo económico, la búsqueda titubeante de nuevas especializaciones para cada uno de los países y, muy particularmente, en Estados Unidos. Conforme a la intuición de Marx, las grandes crisis son episodios decisivos en la historia del capitalismo.

\section{KEYNES, AMPLIADO POR MINSKY: ENDOGENEIDAD DEL CICLO DEL CRÉDITO Y POSIBILIDAD DE UN ESQUEMA PONZI DE LAS FINANZAS}

Con el derrumbe del paradigma del absolutismo del mercado y la profundización de la recesión en 2008-2009, muchos analistas, obligados y forzados, fueron orientados a reconsiderar su apreciación acerca de la herencia keynesiana (Wolf, 2009). En primer lugar, se hizo muy evidente que los mercados financieros 
están dotados de una inestabilidad peligrosa para la prosperidad económica. En segundo lugar, la intervención pública, lejos de ser enemiga de la eficacia, en realidad puede favorecerla. Por último, en situación de depresión y cuando han sido agotados todos los recursos de la relajación monetaria, la política de gasto público y de reducción fiscal recobra, según se espera, toda su eficacia. Sin embargo, hay que ir más allá de estas cuantas máximas, pues lo que nos importa reconstruir a partir de Keynes es el paradigma de las finanzas y de sus relaciones con la economía.

\section{Las bases de una teoría de los mercados financieros realista y ya no normativa}

Como se destacó en el primer capítulo de este artículo, las finanzas modernas se construyeron conforme a la hipótesis de que la serie de cotizaciones pasadas contenía toda la información pertinente y necesaria para la valoración de los activos y los productos derivados. En una época completamente dominada por la revolución de las anticipaciones racionales, los financistas veían el futuro por el retrovisor. Keynes es uno de los primeros en haber introducido a la teoría económica la idea de que es importante escudriñar el futuro, de que probablemente sea útil remitirse al pasado, pero que los medios de análisis y de matematización son limitados. En palabras de Keynes:

Estamos simplemente acordándonos de que las decisiones humanas que afectan el futuro, ya sean personales, políticas o económicas, no pueden depender de la expectativa matemática estricta, desde el momento que las bases para realizar semejante cálculo no existen; y que es nuestra inclinación natural a la actividad la que hace girar las ruedas, escogiendo nuestro ser racional entre las diversas opciones lo mejor que puede, calculando cuando hay oportunidad, pero con frecuencia hallando el motivo en el capricho, el sentimentalismo o el azar (J. M. Keynes, 1936, Teoría general de la ocupación, el interés y el dinero, cap. XII, p. 170).

Keynes responde por adelantado a la objeción de un fundamentalista del mercado: si esto fuera así, ¿acaso los agentes que se dedicaran a encontrar la información pertinente en el camino del porvenir no impondrían gradualmente sus puntos de vista, que a su vez serían diseminados por el intermediario del sistema de precios en las finanzas y en toda la economía? 
El hecho más destacado es lo extremadamente precario de las bases de conocimiento en que han de basarse nuestros cálculos de los rendimientos probables. Nuestro conocimiento de los factores que regirán el rendimiento de una inversión en los años venideros próximos es frecuentemente muy ligero y a menudo desdeñable. [...] De hecho, quienes intentan en serio realizar semejante estimación se encuentran en tal minoría que su conducta no gobierna el mercado (ibidem, capítulo XII, p. 159).

Se piensa, por ejemplo, en la estrategia que introduce, en un portafolio de largo plazo, activos financieros cuyo valor fundamental es notablemente subestimado. Este valor puede prosperar mediante la explotación de lo que el fundamentalista denominaría imperfecciones del mercado, aunque sin modelar la dinámica de conjunto del mercado. A final de cuentas, es necesario que el horizonte y los objetivos sean diferentes a los de los demás actores del mercado, ya que estos últimos - por ejemplo, si son analistas de bolsa- juegan contrariamente con la liquidez del mercado para tratar de anticipar un vuelco en la tendencia del mercado, sea cual sea el valor económico subyacente de los títulos que intercambian.

Podría haberse supuesto que la competencia entre los profesionales expertos, que poseen más juicio y conocimiento que el inversionista privado medio, corregiría las extravagancias del individuo ignorante abandonado a sí mismo. Sucede, sin embargo, que las energías y la habilidad del inversionista profesional y del especulador están ocupadas principalmente en otra parte. Porque la mayoría de estas personas no está de hecho dedicada en primer término a realizar previsiones superiores a largo plazo respecto al rendimiento probablemente de una inversión por todo el tiempo que dure, sino a prever cambios en las bases convencionales de valuación con un poco más de anticipación que el público en general (ibidem, capítulo XII, p. 163).

En el lenguaje de Keynes, la dinámica bursátil emerge de la interacción entre empresa y especulación. El credo de los fundamentalistas es que la racionalidad exige que la empresa prevalezca sobre la especulación. El análisis de Keynes consiste, por lo contrario, en que el establecimiento de mercados financieros profundos y líquidos tiende a favorecer la especulación, la cual se torna cada vez más y más intensa a medida que se incrementa la sofisticación de los instrumentos financieros, pues ésta multiplica los vectores de la especulación. 
Si se me permite aplicar el término especulación a la actividad de prever la psicología del mercado, y la palabra empresa, o espíritu de empresa, a la tarea de prever los rendimientos probables de los bienes por todo el tiempo que duren, de ninguna manera es cierto que siempre predomine la especulación sobre la empresa. No obstante, a medida que mejora la organización de los mercados de inversión, el riesgo del predominio de la especulación aumenta (ibidem, capítulo XII, pp. 166-167).

Anticipando uno de los grandes temas de la sociología de las finanzas contemporáneas, Keynes destaca el carácter socialmente determinado de la preponderancia, ya sea de la empresa o de la especulación, en una economía dada. De manera retrospectiva, es sumamente sorprendente la exactitud de su caracterización de Wall Street, en contraste con la City. Hoy en día, esta caracterización todavía explica la fuerte diferenciación internacional de la crisis de los productos derivados. Además, anticipa una recusación irónica del argumento de los fundamentalistas, según el cual de ninguna manera se debería obstaculizar la autonomía de los mercados financieros, so pena de comprometer la eficacia en la asignación del capital. La amplitud de las pérdidas nominales de los portafolios y de las pérdidas reales en términos de asignación del capital y del trabajo a lo largo de las dos crisis de Internet, y luego del mercado inmobiliario estadounidense, sugiere que no se trata de un tema de orden menor.

Se dice que es raro que un norteamericano invierta, como lo hacen muchos ingleses todavía, "para percibir una renta"; y no será fácil que compre un valor redituable si no tiene la esperanza de una apreciación del capital. Esto es sólo una forma de decir que cuando el norteamericano compra una inversión está poniendo sus esperanzas, no tanto en su rendimiento probable como en un cambio favorable en las bases convencionales de valoración; es decir, que es, en el sentido anterior, un especulador. Los especuladores pueden no hacer daño cuando sólo son burbujas en una corriente firme de espíritu de empresa; pero la situación es seria cuando la empresa se convierte en burbuja dentro de una vorágine de especulación. Cuando el desarrollo del capital en un país se convierte en subproducto de las actividades propias de un casino, es probable que aquél se realice mal. La medida del éxito obtenido por Wall Street, considerada como una institución cuya finalidad social es guiar las nuevas inversiones por los cauces más productivos en términos de rendimiento futuro, no puede presentarse como uno de los triunfos prominentes del capitalismo de laissez faire... (ibidem, capítulo XII, p. 167). 
Una vez que sobreviene una crisis de orden mayor, ¿cómo intentar superarla? La perplejidad de las autoridades estadounidenses en 2008 muestra la dificultad de la conducta de la política económica en un contexto tan atípico. Sobre este tema, Keynes también anticipa una posible interpretación en cuanto al débil impacto de una política monetaria que buscara reducir prácticamente a cero la tasa interbancaria fijada por la banca central. Así, el pesimismo de las perspectivas del porvenir puede ser de tal magnitud que sólo la toma del control por parte de la colectividad de la evaluación del rendimiento a largo plazo de ciertas inversiones puede devolverle la coherencia y la viabilidad a un sistema económico paralizado, primero por el pánico, después por el miedo, el inmovilismo y el refugio en la liquidez.

Por mi parte, soy ahora un poco escéptico respecto al éxito de una política puramente monetaria dirigida a influir sobre la tasa de interés. Espero ver al Estado, que está en situación de poder, calcular la eficiencia marginal de los bienes de capital a largo plazo sobre la base de la conveniencia social general, asumir una responsabilidad cada vez mayor en la organización directa de las inversiones, ya que probablemente las fluctuaciones en la estimación que haga el mercado de la eficiencia marginal de las diferentes clases de capital, calculadas en la forma descrita antes, serán demasiado grandes para contrarrestarlas con alguna modificación factible de la tasa de interés (ibidem, capítulo XII, p. 171).

¿Reevaluación a minima del absolutismo de mercado o renovación de la teoría keynesiana? Las citas anteriores deberían de bastar para convencer al lector del impasse que constituye la primera de las dos estrategias, aún muy presente en los debates estadounidenses y en las organizaciones internacionales: "¡la reglamentación va a asfixiar la innovación y a matar el capitalismo!".

\section{2. ¿Por qué haber abandonado la macroeconomía monetaria y financiera de Keynes?}

No se debería subestimar la ruptura que representa la Teoría general, tanto con el itinerario intelectual del autor como con los trabajos de sus contemporáneos. Indudablemente, en el Tratado de la moneda (1930), Keynes aún era prisionero de la concepción clásica: un primer modelo de economía real proveía un sistema de precios relativos y luego se introducía la función de la moneda para explicar las desviaciones del equilibrio que forman el ciclo económico. El punto de partida 
de la Teoría general insiste en la primacía de la moneda y de sus repercusiones en la economía financiera y, por tanto, en la inversión, la demanda efectiva y el empleo. La economía monetaria de producción de Keynes es entonces una opción radical a la introducción de la moneda a posteriori en un modelo walrasiano de intercambio, en el cual la moneda es fundamentalmente neutral en la escala de un ciclo completo.

La moneda, que es la base de una economía mercantil, también es el origen de una desviación estructural respecto a la Ley de Say que, formulada de una manera ingenua, pretendía que cualquier oferta creara su propia demanda. Así, la moneda permite, por ejemplo, el atesoramiento de los ingresos de ventas anteriores o incluso la redirección de la demanda hacia otros productos y productores. La incertidumbre está así en el núcleo de una economía monetaria. Entonces, al tratar de proyectarse hacia el futuro, las empresas fijan su producción y su inversión: necesitan imaginar la demanda que les será destinada. Éste es el principio de la demanda efectiva. Para llevar esto a cabo, todos los actores económicos deben forjarse expectativas sobre el futuro y, tal como se demostró en la sección anterior, quedan relativamente desprovistos en cuanto se abandona la ficción neoclásica de un mundo estacionario en el cual los individuos terminan por conocer perfectamente los mecanismos que rigen sus interacciones, con tan sólo algunos elementos de riesgo.

En las economías capitalistas maduras el sistema financiero resulta ser la cámara de eco en la que se confronta la heterogeneidad de las anticipaciones, para definir precios y representaciones que se supone se deben imponer a los agentes y explicar las elecciones de producción, de inversión, de consumo y de ahorro. Keynes anticipa la idea de una convención y le da un contenido particular que resulta de la observación de los mercados financieros de su época.

En la práctica hemos convenido tácitamente, por regla general, en referirnos a lo que en realidad es una convención. La esencia de ésta -aunque desde luego no funciona con tanta sencillez- está en suponer que la situación existente en los negocios continuará por tiempo indefinido, excepto cuando tengamos razones concretas para esperar una modificación. Esto no quiere decir que en realidad creamos en la duración indefinida del estado actual de los negocios. Sabemos por experiencia repetida que esto es lo más improbable (ibidem, capítulo XII, p. 161). 
Esta definición de la convención permite a Keynes explicar el fenómeno del periodo que pretende explicar con su teoría: la estabilidad de un desempleo involuntario en la economía británica a lo largo de toda la década de los años treinta. Así, se deducen expectativas desfavorables acerca de las perspectivas futuras de la economía, la cual se encuentra validada ex post por el hecho de que ese pesimismo se incorpora a las evaluaciones, por ejemplo, bursátiles. De este modo, la organización financiera es un componente necesario para la explicación del desempleo: es una innovación teórica considerable respecto a la tradición clásica en la que se inscribían los anteriores trabajos de Keynes. De lo anterior se deduce inmediatamente que moneda y finanzas no son neutrales, ya que sus modalidades de gestión contribuyen en todo momento a la determinación de la actividad económica.

Por consiguiente, en el momento de las grandes crisis, la función del Estado no sólo es la de actuar, en el mejor de los casos, sobre la tasa de interés y el gasto público, sino también intentar reinstalar un regreso a la confianza, haciendo explícita una estrategia que podría polarizar el comportamiento de los agentes privados, quienes, abandonados a su suerte, no consiguen superar la incertidumbre radical que inhibe sus decisiones. Se valora la distancia de esta concepción respecto a la de la visión neoclásica, que considera que la función del Estado se limita a dejar actuar a la competencia de mercados.

La Teoría general provee otra intuición relacionada con las reformas que permitirían evitar la repetición de la crisis de las subprimes. La propuesta más común es tan simple como perniciosa: organicemos, en el mejor de los casos, la transparencia y la fluidez de los mercados financieros. Keynes considera que más bien es necesario aumentar los costos de los recursos en los mercados financieros si se quiere evitar que se repitan y se agraven las burbujas especulativas.

Estas tendencias son una consecuencia difícilmente eludible de que hayamos logrado organizar mercados de inversiones "líquidos". Generalmente se admite que, en interés público, los casinos deben ser inaccesibles y costosos, y tal vez esto mismo sea cierto en el caso de las bolsas de valores [...] La implantación de un impuesto fuerte sobre todas las operaciones de compraventa podría ser la mejor reforma disponible con el objeto de mitigar en Estados Unidos el predominio de la especulación sobre la empresa (ibidem, capítulo XII, pp. 167-168).

¿Acaso esto no es el origen de la propuesta de un impuesto Tobin -desde luego más ligero- cuyo objetivo es desalentar la especulación? ¿Qué economista 
contemporáneo reconocido se atrevería a hacer una propuesta de este tipo, a pesar de ser tan lógica?

\section{Crédito, ciclo y depresión en el capitalismo financiero: ;un homenaje tardío a Hyman Minsky!}

No obstante, la teoría es menos general de lo que pudieron creerlo los fieles keynesianos. John-Maynard Keynes provee gran cantidad de pistas y no escatima en los medios para triunfar sobre la teoría clásica a la Pigou. El embate conceptual es notorio, pero la reconstrucción sigue siendo parcial, ya que le debe mucho al contexto tan particular de la economía británica: un largo periodo de desempleo y de cuasi estancamiento, pero no la dramática depresión de 1929-1932 en Estados Unidos. Por otra parte, para presentarse de una mejor manera como sucesor del modelo clásico, Keynes acepta circunscribirse al tema de la estabilidad de un equilibrio de subempleo.

El gran mérito de Hyman Minsky (1975 y 1982) es haber prolongado y actualizado el embate keynesiano. Minsky reinterpreta la Teoría general como la caracterización de una economía en la que los grandes grupos económicos y financieros buscan utilizar su acceso al crédito para obtener las tasas de rendimiento financiero más elevadas posibles. La dinámica de la formación del cash-flow (flujo de capital), de la obtención de créditos y de sus reembolsos se aleja de la referencia a un equilibrio estático de corta duración para delimitar el perfil de las evoluciones macroeconómicas del capitalismo financiero. Por otra parte, la referencia explícita de los trabajos de Hyman Minsky es principalmente la economía estadounidense posterior a la segunda Guerra Mundial, cuyas características difieren sensiblemente de las de la economía británica. Por consiguiente, una de las interrogantes más trascendentes es la siguiente: ¿bajo qué circunstancias el ciclo correspondiente puede desembocar en el equivalente de la Gran Depresión? Nos percatamos, sin aflicción, de la actualidad que tiene esta pregunta frente a la crisis estadounidense que inició en 2008.

$\mathrm{Al}$ inicio de un auge económico, las empresas presentan un comportamiento de endeudamiento prudente, ya que éstas proporcionan las demandas de crédito anticipado sobre las ganancias y permiten reembolsar tanto el principal como los intereses. Sin embargo, conforme se va reafirmando el vigor del crecimiento, las empresas, que ya adquirieron confianza, aceptan una mayor tasa de endeudamiento, hasta el punto de transformarse en especuladores, en el sentido de que confían en una renovación cómoda del crédito y consideran que ya sólo 
tendrán que pagar los cargos de interés. En algunos casos, las empresas pueden adquirir aún más riesgos, al considerar que, incluso si no tienen los medios para reembolsar los préstamos, la plusvalía registrada les permitirá seguir sin problemas una estrategia de caballería o de pirámide financiera como la que pasó a la posteridad bajo el nombre de Ponzi (gráfica 1).

\section{Gráfica 1. Las dos crisis financieras contemporáneas a la luz del análisis de Minsky}

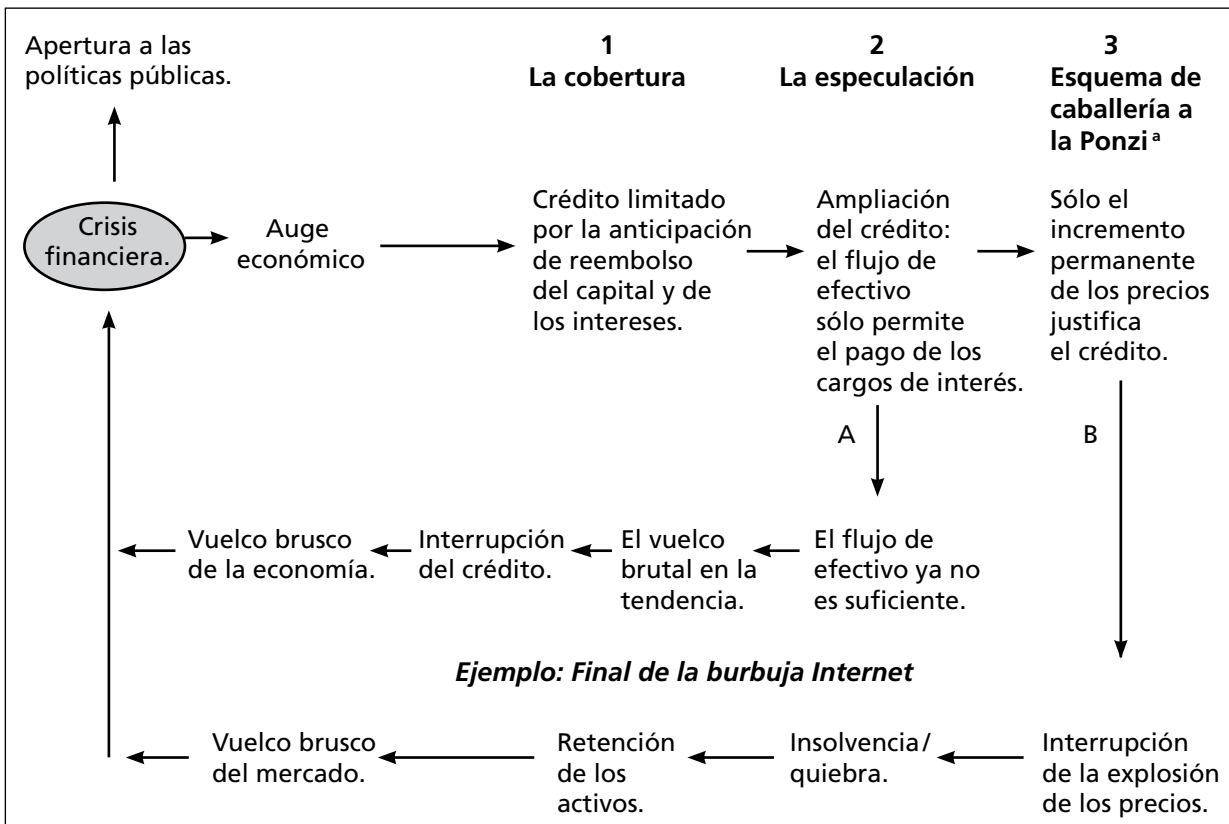

Ejemplo: crisis de las subprime

La diferencia entre las dos crisis:

- La crisis de Internet anticipaba una recuperación del rendimiento del capital productivo, gracias a las TIC, que no estuvo a la altura de las expectativas de las empresas basadas en Internet en la fase inicial.

- La crisis de las subprime presuponía una persistencia indefinida de la explosión de los precios del sector inmobiliario residencial.

${ }^{\text {a }}$ La quiebra de los fondos Madoff corresponde a una característica estrategia Ponzi. Ésta tiene lugar cuando lo que ingresa en el fondo se cruza a prorrata de los retiros, lo cual genera remuneraciones muy superiores al mejor de los rendimientos obtenidos mediante una colocación efectiva en les mercados financieros. 
A partir de la segunda fase se presenta la posibilidad de que el cash-flow, que efectivamente estuvo desbloqueado en un periodo, ya no permita el pago de los intereses: necesariamente, la coyuntura se revierte, puesto que las empresas detienen sus inversiones, los bancos reconsideran su política de crédito fácil y se puede iniciar una carrera por la liquidez a partir de la venta de pánico de los activos financieros o productivos (mecanismo anticipado por Irving Fisher; veáse más adelante). Ante esta descripción, no podemos dejar de pensar en el estallido de la burbuja Internet: cuando la mayoría de las empresas de la nueva economía terminaron de destruir todo el capital que se les había confiado, la economía dio un vuelco brutal.

Si el auge económico se prolonga hasta la fase Ponzi, entonces se comprende claramente que la crisis que resulte de esto sea aún más grave. El vuelco tiene lugar desde el momento en que se desacelera y se revierte la elevación de los precios de los bienes y de los activos que son objeto de la especulación. Esto es lo que sucedió, desde 2007, en el mercado inmobiliario estadounidense: un vuelco que se propagó de inmediato de sector a sector y de activo en activo. Por consiguiente, lo que resulta más interesante es comprender simultáneamente la quiebra de una empresa tan experimentada como lo era Lehman Brothers y el descubrimiento de escándalos financieros vinculados al hecho de que los gestores más respetados practicaban, desde hacía mucho tiempo ya, una estrategia Ponzi: ¿acaso el fondo Madoff no pagaba las salidas de capital con los ingresos de las nuevas entradas - contando con la satisfacción general-, ya que de este modo obtenía rendimientos mucho mayores y estables que sus competidores? Por supuesto, esto funcionaba mientras el volumen de los segundos fuera mayor que el de los primeros.

En estos periodos, la convención financiera "enriquecerse vía las finanzas" se convirtió en la norma y, a pesar de su renombre y experiencia, los establecimientos financieros creyeron y confiaron fondos considerables a un moderno Ponzi. Así, lo que las teorías estándar analizan como aberración, irracionalidad y ausencia de consideración por su propia reputación, son fenómenos típicos de dichos periodos de impulso especulativo: su repetición a lo largo de la historia lo demuestra (Kindleberger, 1978). Por lo tanto, la corrupción y las malversaciones no son las causas de la crisis, sino más bien las consecuencias de una lógica de enriquecimiento llevada al extremo.

De este modo, se abre la posibilidad de que el ciclo desemboque en una pérdida de estabilidad del conjunto del sistema financiero, ya que estos comportamientos se extendieron a casi todas las actividades económicas y el incremento 
en la complejidad de los productos derivados creó interdependencias sin precedentes entre todos los actores, ya fueran financieros o no. Incluso se puede observar que, en los periodos de burbuja, la explosión de los ingresos también permite a los Estados acumular ingresos fiscales vinculados con las ganancias de capital, los bonos, las ganancias de las grandes empresas y con las ventas en el sector inmobiliario. Los colegios, las fundaciones de beneficencia y las universidades colocan sus ahorros en los hedge funds y en los productos más riesgosos. Los ciudadanos estadounidenses que no tienen cobertura social recurren al crédito para financiar sus costos de hospitalización, y las familias de las clases medias financian con créditos los estudios universitarios de sus hijos... sin olvidar que todos ellos son expertos en el arte de hacer malabarismos con sus diversas tarjetas de crédito.

La especulación se convierte así en un deporte nacional en el cual participan incluso los más pobres. La violencia del vuelco en la coyuntura estadounidense se explica por la omnipotencia que habían adquirido las finanzas en la sociedad y la política estadounidenses. Es una lástima que Hyman Minsky, quien murió en 1996, no esté aquí para enriquecernos con su análisis sobre la crisis... sin embargo, sus textos sí siguen aquí para ayudarnos con este diagnóstico. La comunidad financiera terminó incluso por descubrir el interés de este autor, al cual sólo un número reducido de post y neokeynesianos han seguido mencionando en sus investigaciones a lo largo de las décadas que precedieron a la crisis que se inició en 2008.

\section{De Wicksell a Von Neumann: la política de las tasas DE INTERÉS DE LOS BANCOS CENTRALES Y DE LOS AUGES ESPECULATIVOS}

La nueva teoría clásica contemporánea se edificó sobre una doble hipótesis. En primer lugar, a partir de la racionalidad de las anticipaciones, la oferta de moneda sólo ha tenido una influencia transitoria sobre el nivel de la actividad económica, ya que en el modelo walrasiano de base la moneda es neutral en el largo plazo. En segundo lugar, esta misma hipótesis de racionalidad de las anticipaciones otorga a los agentes privados el poder de oponerse completamente a lo que deciden los poderes públicos en materia de gasto público y de tributación. Si bien los planes Bush, luego Obama, reducen la fiscalidad y extienden los programas de inversión públicos, el déficit correspondiente es perfectamente anticipado por la economía privada, cuyo objetivo es aplanar intertemporalmente su consu- 
mo. En consecuencia, los planes de apoyo son nulos y sin valor. Así, con esta teoría, tanto el banco central como el Tesoro estadounidenses se ven exonerados de cualquier responsabilidad en la crisis actual y de cualquier poder para superarla. Esto proviene de la teoría de "la equivalencia ricardiana", que postula la ineficacia fundamental de cualquier política pública.

Esta doble hipótesis es falsa, por lo que es necesario regresar a algunos artículos fundamentales para intuir los mecanismos a partir de los cuales transitan las políticas económicas. Resulta evidente que la responsabilidad de los banqueros centrales -quienes mantuvieron tasas de interés nominales y reales muy bajas, a pesar de que explotaban el crédito y la inflación de los activos financieros e inmobiliarios- se ve comprometida. Dos teorías pueden ayudar a comprender cómo actúa la política monetaria en la senda del crecimiento.

\section{Wicksell: la divergencia entre tasas de interés y rendimiento del capital como puesta en marcha de una fase de expansión}

La primera de las teorías es la propuesta por Knut Wicksell a finales del siglo XIX. Su propósito ya era avanzar en una teoría monetaria diferente del análisis cuantitativo de la moneda, según el cual la oferta de moneda sólo tiene influencia en el nivel de los precios. De hecho, la dinámica económica resulta de la interacción de dos procesos: el de la creación del crédito y el de la formación del capital productivo. En un momento dado, los rendimientos de uno y de otro son diferentes, ya que sus determinantes no son los mismos y sus horizontes temporales son distintos.

En consecuencia, se inicia un movimiento acumulativo: de crecimiento con inflación, cuando la tasa de interés monetaria es inferior a la tasa real de rendimiento del capital; de contracción y de deflación, cuando prevalece la situación inversa. Por tanto, el mecanismo que Wicksell privilegia es el de la formación de capital, y la existencia misma de la moneda de crédito es la que desencadena esta dinámica. El autor lo expresa de manera muy sencilla en su obra Interés y precios (Intérêt et prix, 1898):

Existe un nivel de la tasa de interés sobre los créditos que es neutral respecto al nivel de precios, los cuales no aumentan ni disminuyen. Esta tasa es necesariamente la misma que la que resultaría de la oferta y de la demanda si no se hiciera uso alguno de la moneda y si todos los préstamos se realizaran bajo la forma 
de capital productivo. En otros términos, no es otra cosa sino la tasa de interés natural sobre el capital. ${ }^{*}$

Ahora bien, no hay razón para que las dos tasas coincidan permanentemente. La tasa de interés que se aplica al crédito depende del comportamiento de los bancos, a su vez sometidos a la acción del banco central, y de la organización reglamentaria del sistema financiero. Ésta puede sufrir variaciones discrecionales bajo el efecto, por ejemplo, de la política monetaria. Por otra parte, la tasa de interés natural del capital evoluciona mucho más lentamente, en función de una multiplicidad de decisiones de las empresas y de la eficacia con que éstas utilicen el capital.

Para Wicksell, esta dinámica proviene de la interacción entre la evolución del crédito y la formación del precio de los bienes de capital: cuando la tasa de interés es baja, se incrementa la formación de capital, y el mecanismo puede desarrollarse en varios periodos antes de que intervengan los fenómenos de reequilibrio de ambas tasas.

Para comprender el periodo contemporáneo, basta agregar mercados de activos financieros para tener una explicación sugerente de la repetición de las burbujas financieras. Las tasas de interés (que el banco central estadounidense mantuvo muy bajas) no sólo favorecieron la acumulación, primero, en el sector de las nuevas tecnologías y luego en el de los bienes inmobiliarios (dirigidos a los hogares), sino que además permitieron el desarrollo de estrategias financieras basadas en la permanencia de efectos palanca extremadamente importantes. Los hedge funds, por ejemplo, se volvieron maestros en la adopción de ratio de endeudamiento muy elevados, con el fin de obtener tasas de rendimiento sin precedentes sobre el capital propio. En el periodo contemporáneo, la inflación de los activos financieros reemplazó de manera muy significativa la inflación medida con respecto a los bienes y servicios y el índice de precios al consumo. De acuerdo con esta extensión del modelo de Wicksell, el vuelco tiene lugar cuando se manifiesta la sobreproducción de viviendas y se detiene la especulación sobre los productos derivados. Los datos estadísticos confirman la existencia de esta diferencia duradera, sobre todo en Estados Unidos, y en un menor grado en Europa, entre la tasa de intervención del banco central y la tasa de crecimiento de la economía (véase gráfica 2).

* La traducción se realizó a partir de la cita en francés que aparece en el texto original. 
Gráfica 2. El mantenimiento de tasas de interés bajas como origen de la crisis financiera de las subprime

A. Estados Unidos: tasa directriz, PIB y crédito B. Zona euro: tasa directriz, PIB y crédito

Tasa de interés de los fondos federales (Fed Funds)

PIB (valor, GA en porcentaje)

- - - Crédito bancario en el sector privado (GA en porcentaje)

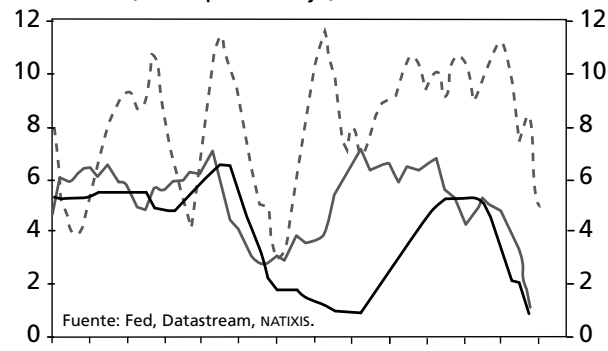

9697989900010203040506070809
Tasa REPO
PIB (valor, GA en porcentaje)

- - - Crédito bancario en el sector privado (GA en porcentaje)

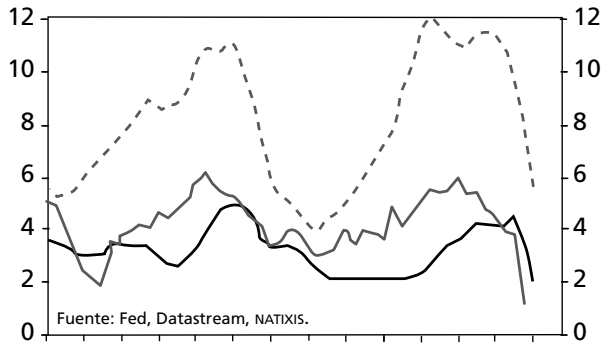

9697989900010203040506070809

Fuente: Patrick Artus (2009a, p. 9).

\section{El modelo de crecimiento de Von Neumann: las burbujas financieras se pueden detectar}

De cierta forma, el tan ignorado modelo de crecimiento óptimo de Von Neumann (1945) permite darle un sentido preciso a la tasa de rendimiento natural del capital propuesta por Wicksell. Indudablemente, nos ubicamos en el marco de una economía en la que el producto del periodo precedente alimenta los insumos de la producción actual, en una economía en la que existe una pluralidad de bienes y procesos productivos. Entonces, bajo ciertas hipótesis técnicas, podemos demostrar que existe una tasa de crecimiento a una tasa constante máxima, la cual es idéntica para todos los procesos productivos, siempre y cuando la economía considerada sea productiva; es decir, que globalmente produzca más productos que insumos consumidos dentro del proceso de producción. Como en este modelo todo el excedente se reinvierte productivamente, la tasa de ganancia es igual a la tasa de crecimiento.

- Por tanto, una de las primeras enseñanzas es que las revoluciones tecnológicas no pueden elevar la tasa de ganancia, salvo que sea prorrateando su eficacia productiva. De este modo, era bastante fácil dudar de la contribución que las tecnologías de la información y de la comunicación hacían a la elevación de la tasa de rendimiento del capital propio (return 
on equity o ROE, por sus siglas en inglés), del tradicional 5\%, que estuvo en vigor en la década de los sesenta, a la tasa de $9 \%$, y luego de $12 \%$ y, aún más, pues terminaron por imponerse tasas del orden de 15 a $16 \%$.

De hecho, el incremento de la ROE para las grandes empresas cotizadas en bolsa tuvo su origen en la debilidad de la tasa de interés de corto plazo y en la búsqueda de efectos palanca cada vez más importantes, a partir del incremento de la tasa de endeudamiento con respecto al capital propio, iy de ninguna manera provino del poderoso incremento de la tasa de rendimiento económico del capital impulsado por las TIC! El fenómeno es muy marcado en Estados Unidos, tierra de elección de la financiarización, pero también se presenta en países como Francia (véase gráfica 3). El auge económico de Internet le debería más a la política de la FED que al dinamismo de Silicon Valley. Por tanto, fue más wickselliano que shumpeteriano.

\section{Gráfica 3. La gestión financiera, más que la revolución productiva, originó el incremento en los resultados de las empresas cotizadas en la bolsa al momento de la burbuja Internet}

Descomposición contable del efecto palanca de las empresas no financieras de S\&P 100 (Porcentaje)

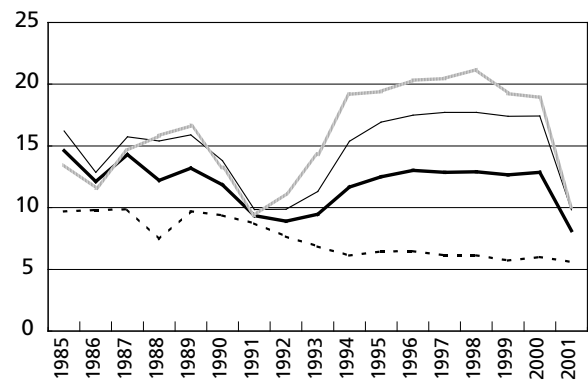

- - Tasa de interés aparente de la deuda (1)

- Rentabilidad económica: ROCE antes de impuestos (2)

- Rentabilidad de los fondos propios, antes de impuestos (3)

- ROE (4)

Fuente: Plihon, Dominique (2002).
Descomposición contable del efecto palanca de las empresas no financieras de CAC 40 (Porcentaje)

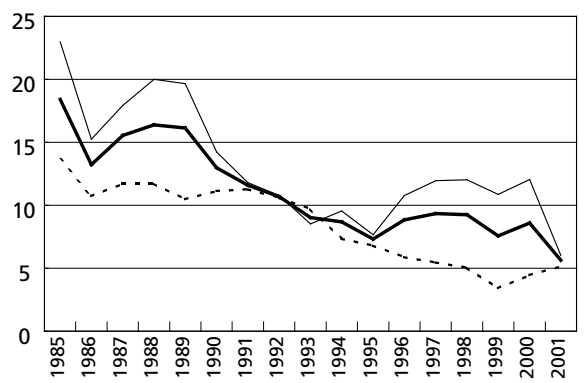

- - Tasa de interés aparente de la deuda (1)

- Rentabilidad económica: ROE antes de impuestos y de la depreciación del goodwill (2)

- Rentabilidad de los fondos propios, antes de impuestos y de la depreciación del goodwill (3)

- Lo dual del programa de búsqueda de la tasa de crecimiento equilibrado radica solamente en la obtención de una tasa de ganancia uniforme para todos los procesos productivos. En este modelo ultrasimplificado, se 
puede entonces calcular la tasa de interés competitiva que prevalecería, en ausencia de los fenómenos de especulación introducidos por el régimen monetario y crediticio. Ésta es estrictamente igual a la tasa de ganancia, que a su vez es igual a la tasa de crecimiento. El interés de este resultado es que provee un criterio para detectar las evoluciones macroeconómicas insostenibles.

Si la tasa de interés real se mantiene muy baja respecto a la tasa de rentabilidad y de crecimiento, la configuración correspondiente no es viable, ya que implicaría una sobreacumulación del capital productivo en el modelo original, aunque éste se puede extender a los activos financieros en la época de la financiarización. Este movimiento necesariamente deberá invertirse debido al tropiezo con el rendimiento económico del capital o con el impulso especulativo. Así, se cuenta con un instrumento para detectar las burbujas financieras, contrariamente a la opinión que fue popularizada por el propio Alan Greenspan. Las autoridades públicas son capaces de detectar evoluciones macroeconómicas desestabilizadoras, aunque no dispongan de información completa acerca de las bases a partir de las cuales los agentes privados toman su decisión. Estas evoluciones también se pueden detectar en el plano macroeconómico cuando, por ejemplo, las cotizaciones bursátiles incorporan, de hecho, tasas de crecimiento al infinito, completamente irreales: las cotizaciones bursátiles de ciertas empresas basadas en Internet, en su fase inicial, suponen una duplicación de sus ventas al infinito (Perkins y Perkins, 1999). Asimismo, la burbuja inmobiliaria japonesa de la década de los ochenta era menos que verosímil dado el caso de que el asalariado promedio hubiera necesitado de varias veces su ingreso en el ciclo de vida completo para adquirir una vivienda en las grandes aglomeraciones niponas. $\mathrm{Mu}$ tatis mutandis, cuando algunos intermediarios financieros otorgan créditos hipotecarios a familias que no tienen los medios para pagarlos, de no ser por un crecimiento permanente del precio del bien inmobiliario que adquirieron de este modo, no cabe duda de que se está formando una burbuja. Entonces, podríamos burlarnos de los economistas estándar que se declaran incapaces de detectar burbujas, jalgo que fácilmente puede hacer un conductor de taxi de Miami en el periodo fasto de la burbuja estadounidense!

$\mathrm{Si}$, a contrario, la tasa de interés real supera por mucho la tasa de crecimiento, la economía está condenada al desendeudamiento, en detrimento de la formación de capital, fenómeno observado en todas las 
fases de endurecimiento de la política monetaria, como respuesta a un impulso del crédito. Esta situación prevaleció en la década de los ochenta en muchos países de la OCDE, entre los que se encontraba Francia. También existe la posibilidad de que, a pesar del rápido descenso de las tasas de interés de los bancos centrales estadounidense y europeo, la amplitud de la caída de la producción traiga consigo un desplazamiento de la inflación a la deflación... al grado de bloquear el proceso de retorno al crecimiento, debido a un desendeudamiento masivo y duradero de los hogares, los bancos y las empresas demasiado endeudadas.

\section{SCHUMPETER, TEÓRICO DE LAS RELACIONES ENTRE CRÉDITO, INNOVACIÓN Y CICLO ECONÓMICO LARGO}

Existe una segunda explicación que retoma el trabajo de Joseph Schumpeter (1911). A partir de Charles Kindleberger (1978 y 1994) y de sus sucesores contemporáneos (Garber, 2000; Reinhart y Rogoff, 2009), esta explicación insiste en la función que desempeñan las innovaciones conocidas como radicales en la posibilidad de desatar crisis financieras mayores.

\section{El crédito, componente necesario de las innovaciones tecnológicas y organizacionales}

En la medida en que el capitalismo incita de forma permanente a la innovación, ya sea técnica u organizacional, periódicamente aparecen algunas innovaciones cuyas perspectivas en términos de mercado y de ganancia son particularmente atractivas. En este entendimiento, otras empresas siguen a los innovadores y se endeudan para poner en práctica de manera más rápida las nuevas técnicas de producción y/o vender los nuevos productos. Así, generan una fase de expansión que la especulación financiera amplifica al grado de provocar la aparición de sobrecapacidades, de las cuales surge una revaluación de las perspectivas de ganancia, la aparición de malas deudas y un vuelco completo de la coyuntura económica.

\section{El modelo se aplica a las innovaciones financieras}

Éste es el esquema que da origen a la mayoría de las crisis financieras contemporáneas. La precipitación de las bancas para ofrecerle créditos a México tras el primer choque petrolero, desembocó en una crisis mayor. La apertura de la cuen- 
ta de capital y la liberalización financiera interna de las economías asiáticas y latinoamericanas desencadenaron el mismo número de crisis: la asiática en 1997, la rusa en 1998, la argentina en 2001. Este esquema concierne también a los países conocidos como desarrollados, de lo cual da testimonio la explosión de la burbuja Internet en Estados Unidos en 2000, como la crisis de los productos derivados del mercado hipotecario estadounidense a partir de 2007. De esta manera, tanto las innovaciones productivas como las financieras pueden desembocar en crisis mayores como las que abundan en el periodo actual.

En los mercados financieros, los participantes buscan evaluar los rendimientos futuros a partir del análisis de la información ofrecida por los datos más recientes sobre los resultados de las empresas, el movimiento de las tasas de interés en el corto plazo, la evolución de las tasas de cambio, las perspectivas del cambio tecnológico, la orientación fiscal, etcétera. El mecanismo está gobernado por anticipaciones, así como por un análisis que se proyecta en el futuro, forward looking. Sin embargo, es posible que algunos participantes del mercado financiero se conformen con un análisis retrospectivo, backward looking, como lo hacen, por ejemplo, los analistas de bolsa para las cotizaciones en bolsa... o todos los ingenieros de las finanzas que calculan el precio de las opciones, gracias al análisis de las series de precios retrospectivos. Como lo demuestran algunos modelos, el comportamiento de los analistas de bolsa o de los seguidores amplifica el movimiento de alza iniciado por el análisis de los agentes mejor informados y equipados para analizar el impacto de una innovación capaz de elevar de forma duradera la tasa de rendimiento del capital en una empresa, en un sector, e incluso en toda una economía.

Los problemas ligados a la incertidumbre, propios de cualquier instrumento financiero, se encuentran exacerbados frente al lanzamiento de un nuevo producto financiero. Los actores deben forjarse una opinión y, ante la falta de observaciones sobre el pasado, se ven restringidos de una $u$ otra manera a basarse en las creencias. Para tomar sólo un ejemplo, la comunidad financiera ha creído en la nueva economía, a pesar de disponer de pocos elementos que le permitieran justificar una casi duplicación de la tasa de rendimiento del capital. Además, la novedad misma del instrumento financiero lleva a tomar en cuenta el hecho de que se abra un periodo sin precedentes, en el cual se desvanecerían las regularidades anteriores. Sin embargo, podría ser que la historia financiera ofreciera valiosas hipótesis relacionadas con la trayectoria de las innovaciones, tanto técnicas como financieras, que deberían dar paso a una nueva época. 
Sin embargo, el horizonte de los actores no pasa de unos cuantos años y el esfuerzo de búsqueda de información y de análisis se centra en las evoluciones más recientes. De esta manera, los actores de estos mercados no tienen más incitación que buscar, en un pasado más lejano, episodios equivalentes: de hecho, a partir de la formación del precio de mercado, tiende a desprenderse la opinión común de que se abre a una nueva época, marcada por rendimientos sin precedentes en cuanto a su nivel y/o estabilidad. El hecho de haber detectado la repetición de una misma secuencia de impulso especulativo constituye el gran mérito de la historia financiera. Hoy en día, estos trabajos son numerosos: en un principio aislados (Kindleberger, 1978) y después se multiplicaron a partir del aumento de la frecuencia de las crisis de mediados de la década de los ochenta (Eichengreen, 2003; Garber, 2000; Reinhart, Rogoff, 2009). La novedad es que los propios teóricos de las finanzas hacen referencia a la sucesión de fases de impulso especulativo para construir modelos que buscan explicar la ineficiencia de los mercados por medio de las modificaciones, más o menos sustanciales, relacionadas ya sea con la hipótesis de racionalidad (Shiller, 2000) o con la organización de los mercados (Shleifer, 2002).

Dicho planteamiento aclara la situación contemporánea: no es la primera vez que una innovación técnica se considera radical y eleva de manera duradera las ganancias. El mismo fenómeno se observó en la década de los años veinte en Estados Unidos; las avanzadas de la organización científica del trabajo eran en ese entonces el equivalente de la reestructuración de las empresas y de las fronteras entre los sectores que estaban bajo el impacto de las tecnologías de la información y de la comunicación.

El propio desarrollo de la liquidez en el mercado bursátil suscita una ola de fusión y de adquisición que, en cierto sentido, reproduce el observado en la década de los sesenta en Estados Unidos (cuadro 1).

\section{De la burbuja Internet a la burbuja inmobiliaria}

En estos dos episodios es posible encontrar los encadenamientos característicos de las fases de especulación anteriores. Lo único que cambia es el soporte del impulso especulativo: la creencia en una revolución tecnológica portadora de una explosión del rendimiento del capital; convicción basada en la apariencia de cientificidad de los nuevos métodos de evaluación y de difusión del riesgo mediante la titulización, lo cual permite un fortalecimiento de la frontera rendimiento/riesgo. 


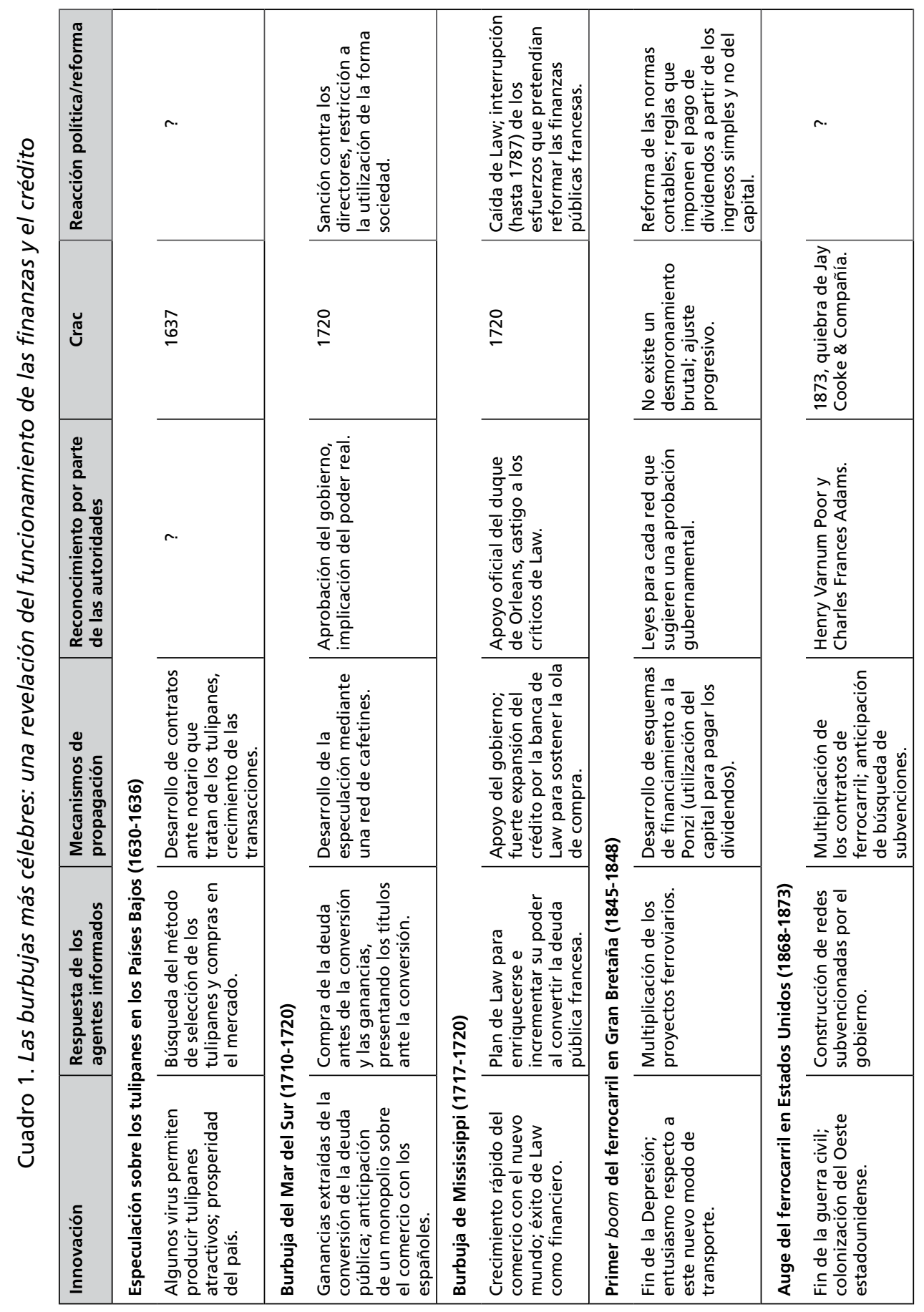




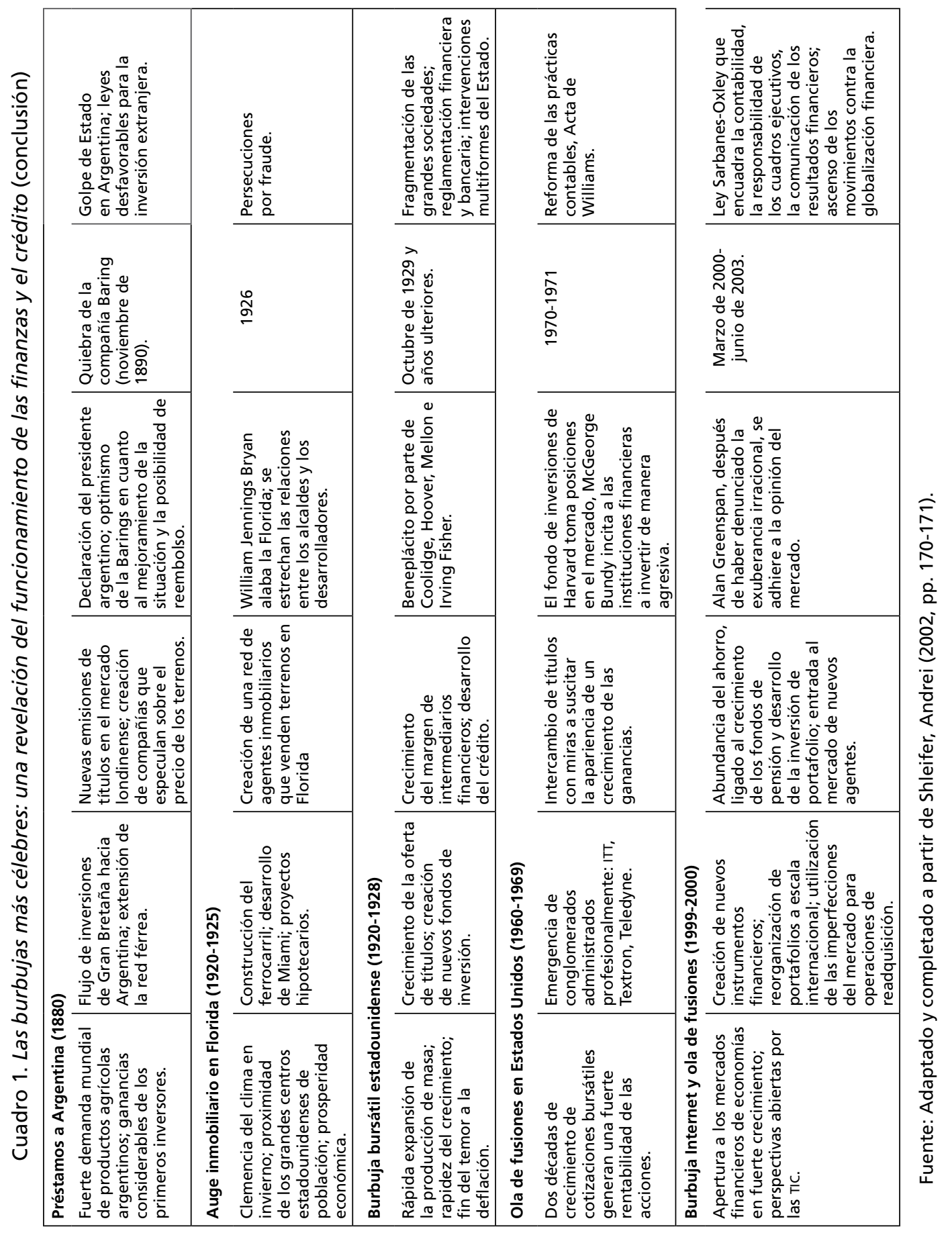


1) En un principio, existe un impulso que se relaciona con una innovación, la cual puede ser técnica (un nuevo método para producir tulipanes o la invención de los métodos de producción en masa), un nuevo instrumento financiero (las acciones de una compañía de navegación), el final de un episodio de guerra (el desarrollo del ferrocarril después de la Guerra de Secesión), el surgimiento de una clientela para nuevos servicios (pasar las vacaciones en Florida, gracias a la renta o la compra de un departamento) o, incluso, las posibilidades abiertas por una nueva coyuntura financiera (la afluencia de liquidez en el mercado bursátil que permite la multiplicación de las OPA-ofertas públicas de adquisición).

2) Los agentes económicos informados adoptan una estrategia selectiva mediante la cual se aseguran de la realidad de los rendimientos prometidos por la innovación. Realizan compras prudentes, sacando provecho de su pericia técnica (¿cómo cultivar los nuevos tulipanes?, ¿qué inmuebles construir en Florida?) o de la información privilegiada de la que disponen, lo cual sucede muy a menudo con las innovaciones financieras. Su comportamiento es totalmente racional y, por sí solo, no conduce a un impulso especulativo.

3) La estrategia de los agentes informados se traduce en el incremento del precio de los productos y, en consecuencia, del precio de los activos financieros de las empresas que participan en su producción. Como una reacción a estas señales de precios, se incorporan al mercado los agentes que tienen poco o ningún conocimiento de la naturaleza de la innovación, pero que confían en una extrapolación del despegue de los precios. Un individuo que nunca en su vida compró acciones y que apenas conoce el funcionamiento de los mercados bursátiles, transferirá una parte significativa de su patrimonio hacia este instrumento financiero. En esta tercera etapa, los agentes seguidores y el crédito desempeñan una función determinante en la escalada especulativa.

4) El impulso tiene aún más vigor cuando una autoridad autentifica la realidad de las promesas realizadas a los pequeños ahorradores $\mathrm{y}$, de manera más general, a los agentes seguidores. En la burbuja del Mississippi, el gobierno francés dio su apoyo oficial a Law. En la década de los años veinte, en Estados Unidos el renombrado economista Irving Fisher declaró que la escalada bursátil y la prosperidad de la economía estaban hechas para durar, diagnóstico que mantuvo hasta la víspera del estallido de la crisis. En el periodo contemporáneo, la curva de la burbuja Internet tuvo lugar cuando Alan Greenspan, quien anteriormente había denunciado la exuberancia irracional, se adhirió a 
la opinión de los mercados, al declarar que los agentes privados saben mejor que el banquero central cuál debe ser la cotización de las acciones.

5) Cuando este movimiento alcanza su máximo, estamos cerca del vuelco brutal mediante el cual se manifiesta el hecho de que los rendimientos obtenidos son muy inferiores a los rendimientos esperados, ya sea a causa de la erosión endógena de los rendimientos, a partir de la sobreacumulación, ya sea como respuesta a una mala noticia, aparentemente menor, pero que desencadena un reajuste de las visiones sobre el futuro. Otra posibilidad es que los agentes mejor informados consideren que, tomando en cuenta el nivel alcanzado por el precio de los activos, sea prudente liberarse vendiendo los suyos.

6) Última secuencia: las autoridades políticas, frente a la gravedad de las consecuencias sociales y políticas del crac, se ven obligadas a intervenir; menos para buscar a los culpables ${ }^{1}$ que para introducir reglas y reformas que eviten la repetición de estos episodios y restablezcan la confianza, ya que sin esta última los mercados no pueden funcionar. En la mayoría de los casos, estas medidas lograron que se olvidara la crisis anterior, al grado de que pudo iniciarse un nuevo ciclo: cualquier innovación que golpee los espíritus es capaz de iniciar una nueva fase de expansión y un posterior impulso especulativo (gráfica 4).

Gráfica 4. De una innovación considerada importante al mimetismo que desemboca en la fragilidad financiera

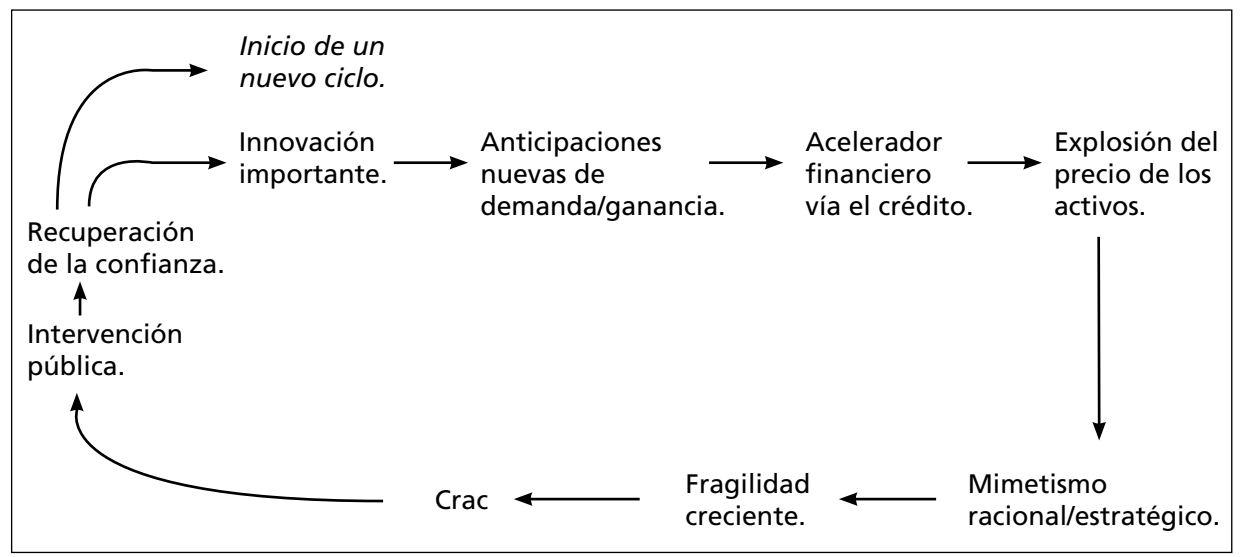

${ }^{1}$ ¿En qué momento las autoridades de Estados Unidos pusieron en marcha una investigación para determinar las responsabilidades en la crisis de las subprime? 
A la luz de este esquema se propone analizar la última década en materia de innovaciones financieras, principalmente en Estados Unidos ( $c f$. cap. III, infra).

\section{FISHER Y LA TEORÍA DE LAS DEPRESIONES OCASIONADAS POR EL EXCESO DE ENDEUDAMIENTO}

Se conoce a Irving Fisher como un gran teórico del equilibrio intertemporal, dentro de una perspectiva típicamente neoclásica. Efectivamente, le debemos el haber elaborado una teoría de la tasa de interés y de los métodos que permite medir el capital. Sin embargo, este componente de sus trabajos no es a lo que generalmente se recurre, sino más bien a su análisis de las depresiones y de las deflaciones generadas por los intentos de desendeudamiento de agentes económicos golpeados por el vuelco brutal de una coyuntura que anteriormente era muy favorable, gracias a la abundancia de créditos (Fisher, 1933).

\section{Un antídoto para contrarrestar la creencia en el poder de los mecanismos de mercado para superar las crisis financieras}

Este análisis se torna más interesante debido a que pretende corregir un dramático error de previsión de Irving Fisher: confiado en que las cotizaciones bursátiles medían el valor efectivo de las empresas, Fisher emitió un pronóstico completamente optimista respecto a la persecución de la llamarada de las cotizaciones bursátiles, que desgraciadamente desembocó en el viernes negro de octubre de 1929. Él quedó arruinado, pero a él mismo le debemos todo el honor de poner nuevamente en cuestionamiento la creencia en la autorregulación de los mercados financieros. ${ }^{2}$

La actualidad de este texto, que ha pasado prácticamente inadvertido entre los economistas contemporáneos, es innegable. Si los teóricos neoclásicos se obstinan en analizar exclusivamente los equilibrios estables, las dos únicas explicaciones de las crisis son, ya sea la aparición de choques exógenos y de gran amplitud (sin embargo, ningún meteorito ha caído sobre Wall Street), o bien una irracionalidad pasajera que se hubiera apoderado de los participantes del mercado; y el desmoronamiento de los fondos Madoff queda como anillo al dedo para dar una pizca de verosimilitud a una hipótesis tan poco pertinente. ¿Acaso las fi-

\footnotetext{
${ }^{2}$ iEs una pena que los autores de la debacle de las subprime no hayan sufrido una quiebra personal! De hecho, los más poderosos conservaron remuneraciones exorbitantes. ¿Acaso ésta sería una explicación para su persistente creencia en el absolutismo del mercado (ver capítulo V, infra)?
} 
nanzas modernas no se han construido sobre la explotación, a todos los niveles, de la hipótesis de racionalidad? Irving Fisher tuvo la osadía de volver a poner en duda la hipótesis de un regreso automático al equilibrio: la voluntad de reducir el endeudamiento desemboca en ventas de pánico, las cuales precipitan una caída de los precios, que a su vez incrementa el peso de la deuda en términos reales. Bajo ciertas condiciones, se puede iniciar un círculo vicioso, cuyo ejemplo más sugerente es el de la depresión estadounidense de 1929 a 1932. Así, el modelo fisheriano de depresión reúne las intuiciones de la escuela sueca y las de la teoría keynesiana.

En términos teóricos, esto significa que la existencia de restricciones de liquidez invalida el modelo walrasiano de formación de los precios.

\section{Una explicación sugerente de la brutalidad y la amplitud de la crisis de las subprime}

Este marco analítico, concebido para dar cuenta de la gran depresión de la década de los años treinta en Estados Unidos, en realidad aclara las razones de la brutalidad del vuelco coyuntural originado por el brusco cambio en el mercado inmobiliario. Por un lado, el mercado inmobiliario y los créditos hipotecarios asociados a él reproducen mutatis mutandis los encadenamientos de la etapa entre las dos guerras. No obstante, por otro lado, es necesario tomar en cuenta la multiplicación de los activos financieros que tuvo lugar desde entonces: las ventas de pánico en masa resultan del intento de realización de los productos derivados en mercados que se volvieron ilíquidos. De ahí se deriva una dramática caída de los precios de los activos, cuyas cotizaciones bursátiles amplifican aún más la caída (gráfica 5).

\section{Los riesgos de un doloroso ajuste depresionista}

Los dos círculos viciosos pueden incluso reforzarse uno al otro, pues el bloqueo del crédito tiene a su vez un efecto retroactivo, primero sobre el sector inmobiliario y luego sobre toda la economía. ¿Acaso no resulta significativo que en Estados Unidos la inflación se haya desacelerado al grado de desembocar en una estabilidad de los precios al consumo y en una baja de los precios al por mayor a lo largo del primer trimestre de 2009? La carrera por la liquidez también afecta a los bancos, que además están sometidos al juicio permanente de la comunidad financiera a partir de la formación de las cotizaciones bancarias. A partir del mo- 
mento en que las pérdidas se acumulan, la evaluación de los mayores bancos de Estados Unidos sufre una caída casi vertical, una caída que la intervención pública masiva con miras a recapitalizarlos no logra frenar. En este sentido, el desmoronamiento de CitiGroup es ejemplar (gráfica 6).

\section{Gráfica 5. Irving Fisher: del equilibrio automático de los mercados a la posibilidad de una depresión acumulativa con deflación}

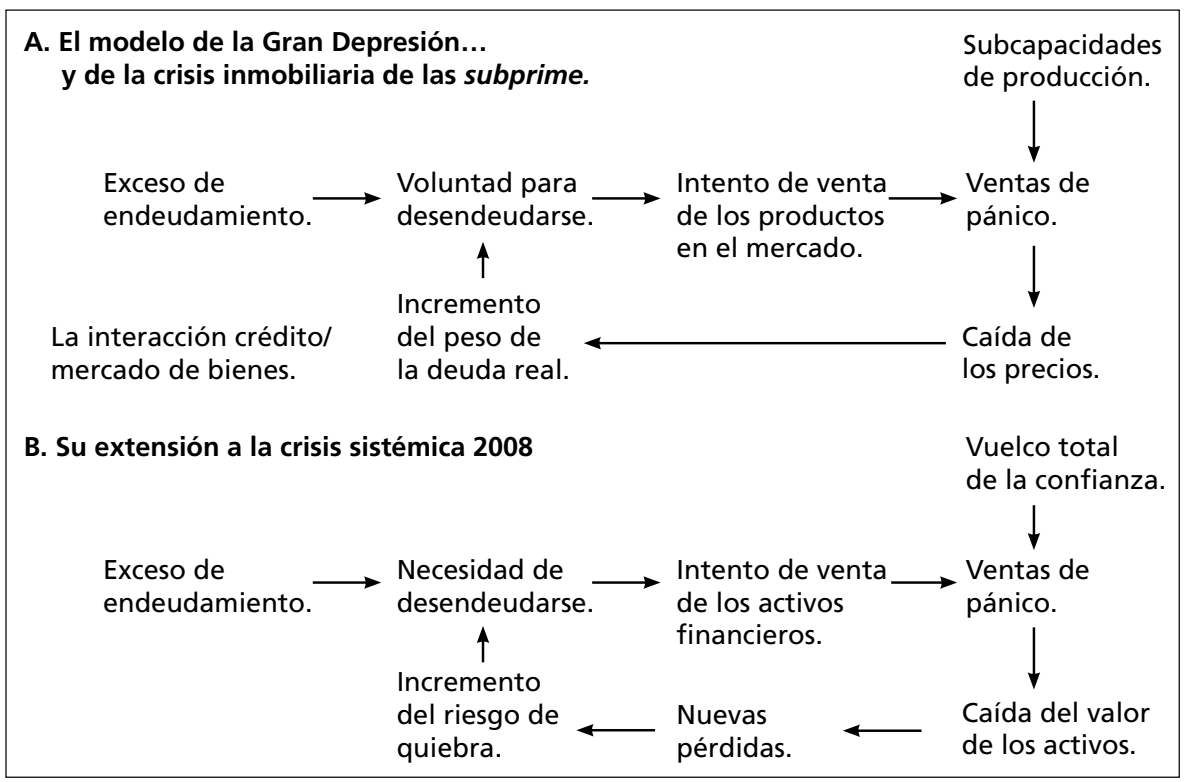

Gráfica 6. El ejemplo del desmoronamiento de las cotizaciones bursátiles de CitiGroup

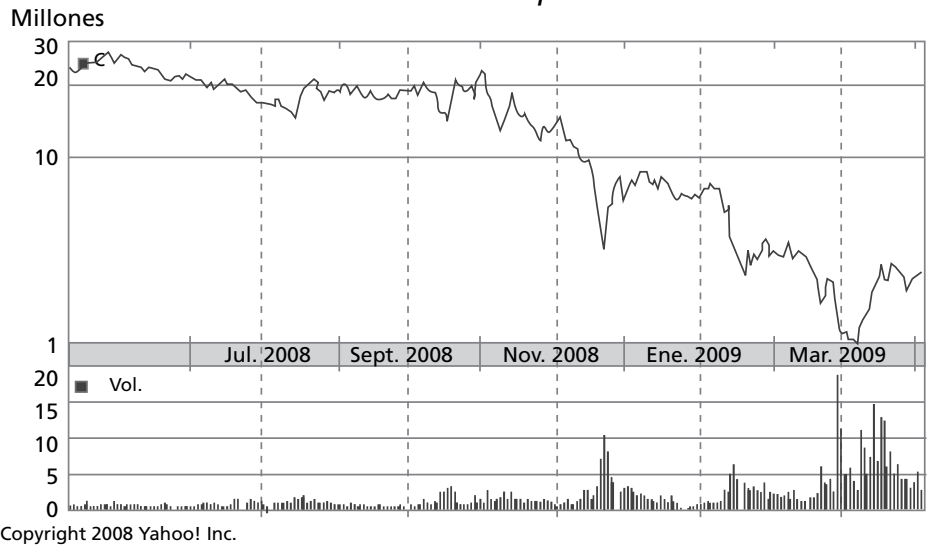

Fuente: http://uk.finance.yahoo.com/q/bc?s=C, 4 de abril de 2009. 
Después de esto, no resulta sorprendente que los analistas del Financial Times o de The Economist terminaran considerando que el mecanismo propuesto por Fisher es una de las claves para la explicación de un desmoronamiento brutal, el cual se percibía como imposible en el marco de la creencia en los mercados autorregulados.

\section{KNIGHT: DE LA BÚSQUEDA DESENFRENADA DE LA GANANCIA COMO TOMA DE RIESGOS A LA ANGUSTIA GENERADA POR UNA INCERTIDUMBRE SISTÉMICA}

Si se interrogara a los dealers y a los diseñadores de productos derivados acerca de su percepción del economista teórico que es capaz de ofrecer una justificación de su práctica, la mayoría de ellos rechazaría la pertinencia de la pregunta: más bien evocarían a los padres fundadores de la economía financiera de mercado, tales como Markowitz (1952), Black y Scholes (1973). Sin embargo, ¿exactamente cuál es la teoría del valor implícita en el cálculo de las opciones, los swaps y otros productos derivados?

\section{De la cobertura del riesgo a la creación de nuevos riesgos}

De hecho, Frank Knight (1921) fue quizás el primero de los economistas que afirmó de manera enérgica que el origen de la ganancia estaba vinculado con la toma de riesgos, cuyo resultado es la remuneración. Esta concepción le conviene perfectamente a las finanzas contemporáneas, cuyo propósito es cubrir y/o transferir los riesgos.

Así, de acuerdo con Knight, cualquier agente que no asuma riesgos no tendrá derecho a la recompensa de las ganancias. No obstante, se trata de una abstracción certera respecto a la multiplicidad de mecanismos que contribuyen a la ganancia en una economía capitalista. Por ejemplo, ¿acaso las ganancias de las empresas chinas del sector textil remuneran la toma de riesgos o bien provienen, esencialmente, de las ganancias vinculadas con la eficacia de una organización productiva y la debilidad de los salarios? Se habrá reconocido aquí la concepción clásica o incluso marxista de la ganancia. De la misma manera, ¿acaso se debe considerar que los notables ganancias de la empresa Coca-Cola proceden de una permanente toma de riesgos? Evidentemente, se trata más bien de la construcción de una imagen que le permite acceder a ganancias oligopólicas. Tanto las estrategias de innovación como las de construcción de imagen de marca son otras 
fuentes de generación de ganancias que podrían calificarse como schumpeterianas. Por supuesto, a los mecanismos marxistas y schumpeterianos se agrega la concepción de Knight... aunque esta última no podría agotar el análisis de las fuentes de la ganancia y de su evolución.

He aquí lo que explica la explosión de la actividad financiera y su cuasi interrupción en septiembre de 2008. Resulta indudable que, para un financiero, el riesgo es la materia prima de su actividad. En un primer momento, éste puede conformarse con cubrirlo contra remuneración: es la función de los mercados de cobertura. Pero, en un segundo momento, resulta sumamente tentador crear riesgos específicos con el fin de extraer remuneración: de esta manera, surgen opciones y swaps, de títulos en producción de derivados de derivados; desde la década de los noventa, los financieros crearon infinidad de productos financieros que en realidad son apuestas sobre el futuro. Entonces, el motivo de especulación tiende a dejarse llevar por el de la cobertura, de manera que se asiste a una explosión sin precedentes de instrumentos financieros cada vez más complejos, ya que descansan en una conjunción de riesgos cada vez más difíciles de controlar. Esto no parece importar, pues en cada una de las etapas de la escalada en complejidad, los actores de las finanzas alcanzan remuneraciones que deberían compensar la toma de riesgos... lo cual demostrará ser excesivo cuando el afán de ganancia conduzca simultáneamente a la imprudencia y a la arrogancia.

\section{La toma de riesgos como fuente de ganancia: uno de los orígenes de la crisis}

Así, la concepción de Frank Knight ayuda a comprender el núcleo del impulso especulativo en el transcurso del cual Wall Street impuso progresivamente al resto de la economía estadounidense la idea de que la ganancia no era más que la toma de riesgos... al grado de que las competencias y los capitales se desvían de la banca tradicional y de las actividades productivas, concebidas como lugar de una concepción arcaica de la ganancia, para impulsar una hipertrofia del sector financiero (gráfica 7).

Lo que originalmente era la cobertura de un riesgo preexistente se transforma en un proceso de creación de nuevos instrumentos, portadores de riesgo y articulados unos con otros, los cuales desembocan en una interdependencia sistémica. Basta con que se revierta el incremento de los precios en el mercado inmobiliario para que el conjunto de estos riesgos se manifieste y se traduzca en pérdidas que amenacen la liquidez y la solvencia de un gran número de entidades 
Gráfica 7. Dos indicadores de la financiarización

A. Ganancia del sector financiero en porcentaje del PIB (1948-2007)

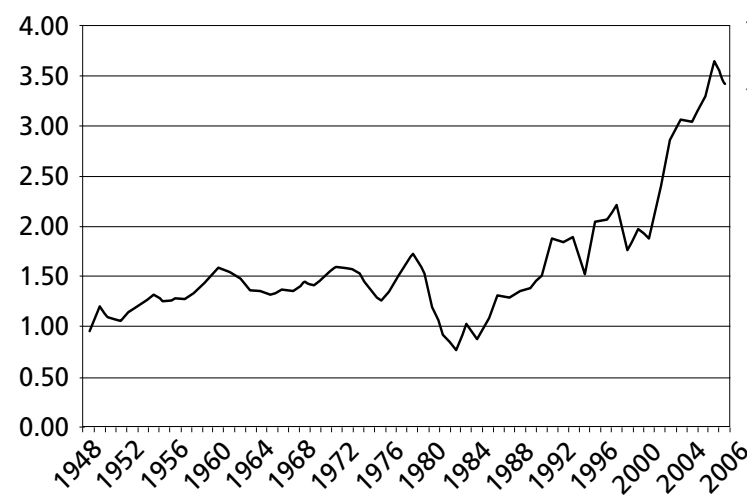

B. Total de los activos financieros en porcentaje del PIB

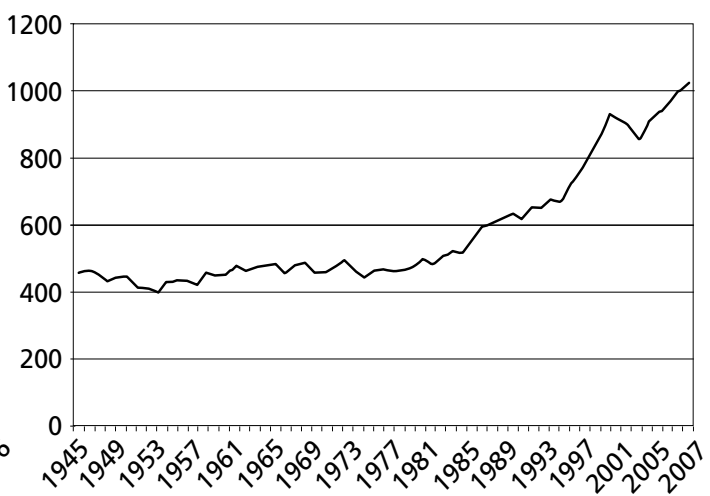

Fuente: Crotty James, y Gerald Epstein (2008), "The Costs and Contradictions of the Lender-of-Last Resort Function in Contemporary Capitalism: The Sub-Prime Crisis of 2007-2008", Political Economy Research Institute (PERI), documento de trabajo, Amherst, University of Massachusetts, 2-3 de mayo.

financieras de Estados Unidos. La amplitud de las pérdidas está a la medida del fuerte incremento de las ganancias extraídas de la innovación financiera.

\section{La parálisis de las finanzas una vez que el riesgo se transforma en incertidumbre sistémica}

Frank Knight ofrece una segunda lectura teórica muy útil para entender la tregua del sistema financiero estadounidense que tuvo lugar en septiembre de 2008. Por oposición a los periodos en los que los métodos estadísticos permitieron evaluar los riesgos, en otras circunstancias, por ejemplo, cuando surge una crisis financiera sistémica, la experiencia extraída del pasado ya no tiene utilidad alguna y los agentes pierden sus puntos de referencia respecto a sus decisiones de inversión y de crédito. En este caso vale la pena recurrir al concepto de incertidumbre y ya no al de riesgo. En septiembre de 2008, los actores de las finanzas, de la economía y de la política, incluso los más informados, fueron incapaces de prever cuáles serían las condiciones de crédito, las perspectivas de demanda o incluso la orientación estratégica del gobierno. Entonces, se derrumbó la problemática de la economía estándar, según la cual, en condiciones de información perfecta, los agentes pueden desplegar estrategias óptimas de cobertura del riesgo, cuya conjunción ofrece un equilibrio de mercado. 
La situación de espera, la búsqueda de liquidez y la aversión al riesgo son características de dicho periodo. ${ }^{3}$

A riesgo de exagerar un poco, podríamos anticipar la idea según la cual Frank Knight puede convertirse en una de las referencias clave para los analistas de la crisis actual (gráfica 8). La búsqueda, a cualquier precio, de la ganancia como remuneración del riesgo desemboca en un exceso de confianza y de endeudamiento que se acaba con el estallido de la burbuja correspondiente y de los paradigmas que justifican la inocuidad (Bouchaud, 2009; Cont, 2009).

Gráfica 8. La crisis de las subprime a la luz de la teoría de Frank Knight: riesgo, ganancia e incertidumbre

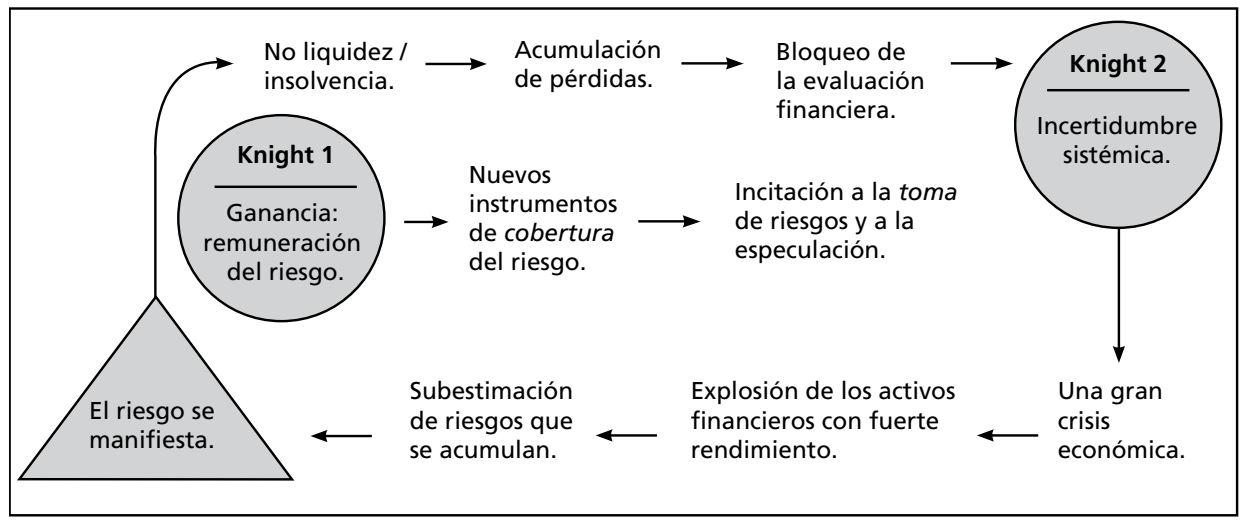

\section{HAYEK: LA PRIVATIZACIÓN DE LA FORMACIÓN DE LOS PRECIOS DE LOS PRODUCTOS DERIVADOS DESTRUYE LA INFORMACIÓN NECESARIA PARA EL FUNCIONAMIENTO DE LOS MERCADOS FINANCIEROS}

Estos errores de evaluación del riesgo no serían demasiado graves si se establecieran en un sector bien definido. No obstante, pueden tener una influencia determinante sobre la dinámica macroeconómica, muy particularmente en materia de asignación de capital, si se generalizan y se transmiten al conjunto de los activos

\footnotetext{
${ }^{3}$ En la Cumbre de Davos del invierno 2008-2009, la declaración de los grandes jefes de empresa reunidos para esa ocasión no era otra que la siguiente confesión de impotencia: "Me veo en la incapacidad de prever cuál será el nivel de actividad de mi empresa para el año 2009 ya que me enfrento a demasiadas incertidumbres". El reconocimiento de la pertinencia de la oposición riesgo/ incertidumbre y del carácter sistémico de la crisis llamada de las subprime está implícito.
} 
financieros, que son cada vez más complejos conforme nos alejamos de la relación de crédito de base.

1) Todo comienza con la aplicación de la estrategia de acceso a la vivienda de categorías sociales que no disponen de ingresos o de garantías suficientes. Este relajamiento del control del crédito se traduce en su propia explosión y en la baja calidad de los créditos. Esto se manifiesta en el incremento continuo de las fallas de pago entre 2003 y 2007 (gráfica 9).

\section{Gráfica 9. Deterioro continuo de la calidad del crédito hipotecario en Estados Unidos desde 2003}

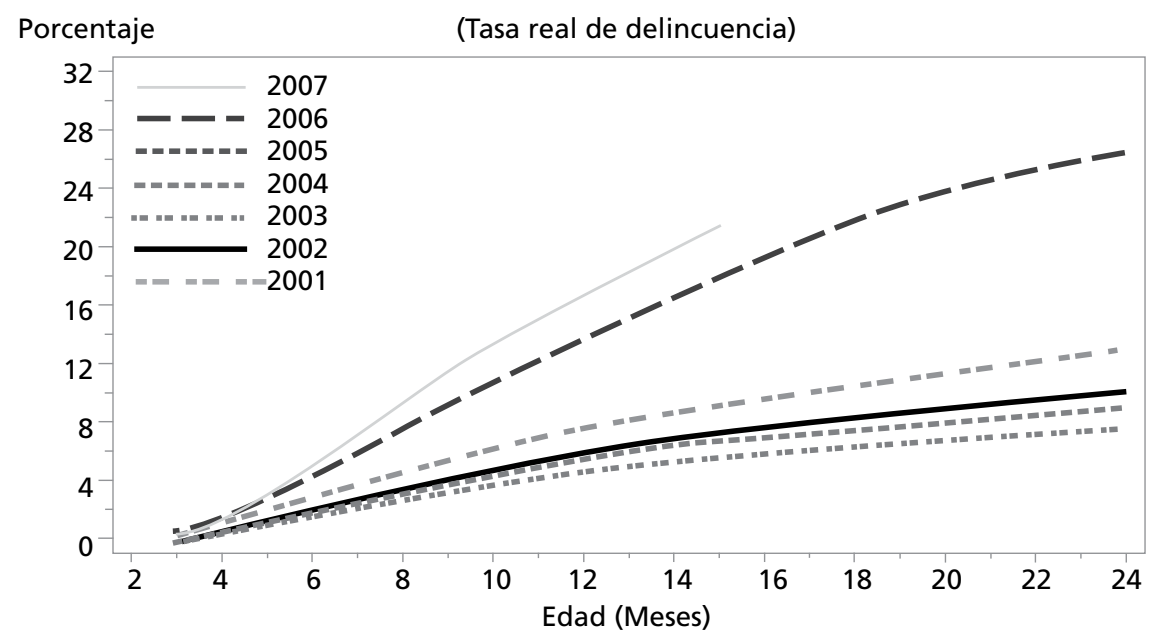

Fuente: Yuliya Demyanyk y Otto van Hemert (2008, p. 1).

2) El deterioro de la calidad de los activos financieros no se detiene aquí, pues el recurso masivo a la titulización, es decir, el reagrupamiento de estos diversos créditos, su recorte en tramos y su transformación en obligación difunden esta pérdida de calidad al conjunto del sistema financiero (gráfica 10).

3) Las agencias calificadoras, a las que la colectividad pública les ha delegado la evaluación del riesgo asociado a los activos, introducen la confusión al adoptar la misma clasificación que para los activos financieros primarios. De esta manera, conducen a atribuir la calificación triple A a los productos derivados especialmente peligrosos, desde el momento en que se revierte la coyuntura, ya que se caracterizan por una fuerte linealidad. Además, incluso si no disponían de la información pertinente, ya les atribuyeron la mejor de las 
Gráfica 10. Explosión del volumen de la titulización; deterioro de la calidad (Porcentaje)

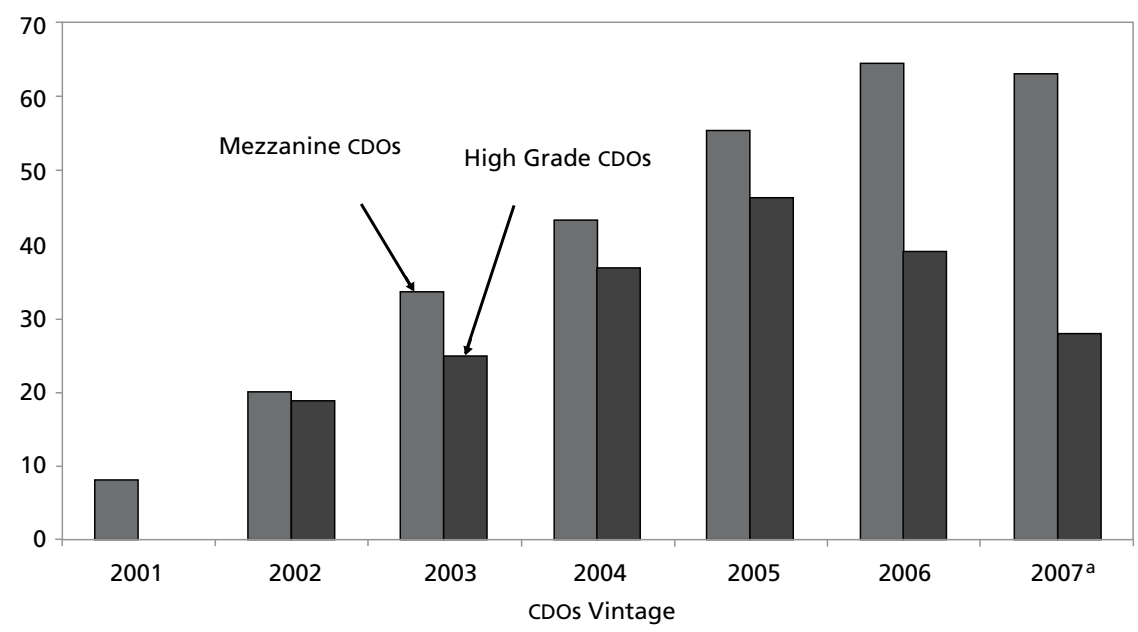

a 2007 vintage includes deals completed through September Fuente: Standard and Poor's.

calificaciones a los productos correspondientes, debido a que habían sido emitidos por una gran entidad financiera y, por tanto, habían sido inmunizados contra el riesgo de quiebra. ¡Éste fue el caso de los CDS propuestos por AIG! Desde entonces, las agencias calificadoras, lejos de acotar los riesgos emergentes y de proporcionar señales precursoras de crisis, se limitan a adoptar el perfil cíclico del conjunto de los demás actores (Calomiris, 2009). Los riesgos se reajustan de manera ex post, es decir, una vez abierta la crisis (cuadro 2).

Cuadro 2. La incapacidad de las agencias calificadoras para acotar los riesgos emergentes

\begin{tabular}{|c|c|c|}
\hline \multicolumn{3}{|c|}{ Upgrades et downgrades: tranche d'ABS } \\
\hline Annés & Upgrades & downgrades \\
\hline 2006 & 205 & 77 \\
\hline 2007 & 233 & 61 \\
\hline 2008 & 250 & 505 \\
\hline
\end{tabular}

Fuente: Patrick Artus (2009 b). 
4) Las nuevas normas contables desempeñarán un papel determinante, tanto en la fase de euforia como al momento de la debacle. En primer lugar, el principio de mark to market llevó a ratificar el valor especulativo de los mercados bursátiles como una evaluación digna de confianza. En segundo lugar, y aún peor, el segundo principio de mark to model permitió a las propias entidades financieras fijar de manera asimétrica el precio de sus mercados de común acuerdo: los OTC. Como los modelos utilizados son fundamentalmente los de Black y Sholes, éstos excluyen los elementos extremos, aunque hayan sido frecuentemente observados en el mercado bursátil. A pesar de que son claramente falsas a la luz de los análisis de Benoît Mendelbrot, estas evaluaciones financieras se desarrollan con una rapidez extrema, en la euforia general, ya que ofrecen cómodas ganancias. Estos modelos no han acotado la realidad del riesgo en el que se incurre una vez que estalla la burbuja inmobiliaria (gráfica 11).

5) Una vez que el vuelco tuvo lugar, todas las entidades financieras fueron presas de una incertidumbre radical, relacionada con el valor de sus activos y

\section{Gráfica 11. Una crisis característicamente hayekiana: la erosión del contenido informacional del precio de los activos financieros}

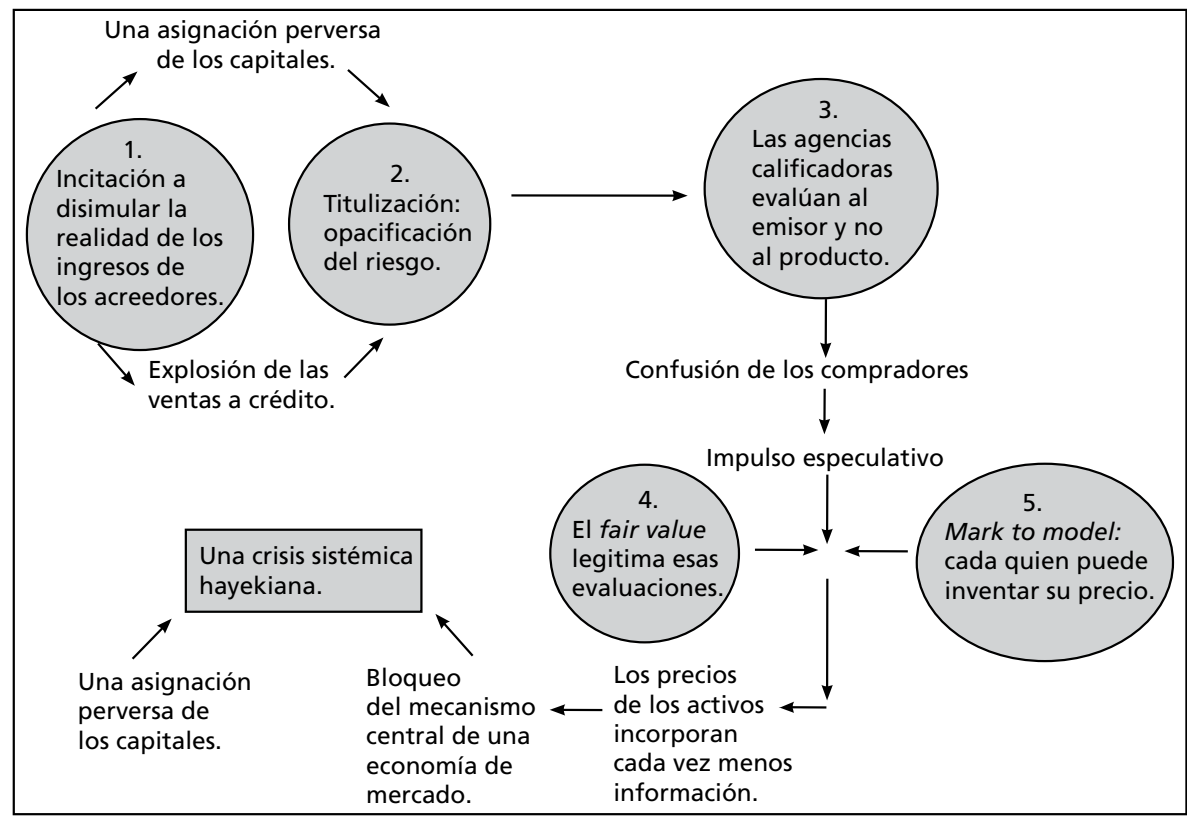


sus pasivos. Bajo el efecto de las ventas de pánico, las cotizaciones bursátiles se desmoronaron y los aprendices de brujo descubrieron -un poco tardela perversidad del fair value. Última ironía: los inventores de los productos derivados, y después de los derivados de derivados, se dieron cuenta de la impotencia de sus modelos para definir una nueva evaluación, dado el desmoronamiento de las hipótesis que planteaban aproximaciones aceptables durante el periodo de auge: agotamiento brutal de la liquidez de los mercados financieros y ruptura de la estabilidad macroeconómica. Temerosos del ridículo, exigen al Tesoro estadounidense organizar un mercado de sus productos tóxicos; una misión imposible puesto que la artimaña consistía en elaborar productos ad hoc para cada cliente; y, por consiguiente, inconmensurables.

Por tanto, no resulta abusivo anticipar una hipótesis paradójica. La crisis de la década de los años treinta en Estados Unidos se derivó claramente de un desequilibrio estructural del régimen de acumulación (una ganancia demasiado elevada que prohibía la realización de la producción). Así, se podía calificar como crisis keynesiana, ya que estaba vinculada a la debilidad de la demanda efectiva y a la difusión de un pesimismo que inhibía los espíritus animales que se encontraban en el núcleo de la decisión de inversión. La crisis que se abrió en 2007-2008 manifiesta una originalidad certera: la innovación financiera contribuyó a la desaparición progresiva del contenido informacional del sistema de precios de los activos financieros. La asignación perversa del crédito, del capital y de los talentos que de ellos derivan, dibujan perfectamente una crisis heyekiana, en el sentido de su artículo fundador (Hayek, 1945). Sin embargo, imperturbablemente, los expertos de ayer que se ven privados de su optimismo digno del Doctor Pangloss, se aferran desesperadamente a Keynes, como principio de inteligibilidad de la crisis, jautor que, por cierto, no conocen bien!

Así, la crisis de la teoría estándar y la crisis económica aparecen estrechamente ligadas. Pero no es seguro que la amplitud de la crisis económica y social sea suficiente para desestabilizar a la mayoría de los economistas que siguen creyendo que las hipótesis estándar permiten, sin problema, cuando menos ex post, analizar una crisis finalmente banal.

\section{LOS GRANDES ECONOMISTAS DEL PASADO: ¿MEJORES LECTORES DE LA CRISIS DE LAS SUBPRIME?}

En realidad, las referencias precedentes permiten una respuesta a dos de las interrogantes del periodo post subprime: 
- ¿Acaso los artículos y obras publicados en el transcurso de los últimos cinco años bastan para resumir los conocimientos acumulados por los economistas durante dos siglos de investigación? No, ya que se ha impuesto un absolutismo del mercado que, por principio, prohíbe la comprensión de las crisis financieras.

- El desmoronamiento de ese paradigma, de las técnicas asociadas a él y de las políticas que justifica, ¿acaso significa que no contamos con ninguna herramienta para analizar y luego superar la crisis actual? La respuesta es negativa, pues aunque no contáramos con una respuesta completamente irrefutable, la relectura de algunos de los grandes autores nos ofrece hipótesis útiles para la reconstrucción de un paradigma alternativo.

A pesar de que la comunidad de los economistas ya no le preste atención, Karl Marx está más vigente que nunca (Marx, 2009). Las crisis no son exógenas, sino la consecuencia directa de la dinámica impulsada por el capitalismo. El crédito le otorga dinamismo a las fuerzas productivas y simultáneamente convierte las crisis financieras en más probables y graves. Estos últimos constituyen episodios principales en la transformación de las formas de organización económica y sociales... ¡incluso si esto no significa un movimiento irreversible hacia el socialismo! Por último, la fuerza del capitalismo para crear nuevas interdependencias entre espacios económicos promueve la mundialización y el hecho de rebasar los Estados-nación.

John-Maynard Keynes es el gran teórico de un capitalismo que se volvió financiero e incapaz de asegurar de manera duradera el pleno empleo y la satisfacción de las necesidades sociales. Keynes demuestra que los mercados financieros modernos están lejos de garantizar una asignación eficaz del capital, de tal manera que la intervención pública es un componente esencial del capitalismo contemporáneo. Le debemos a Hyman Minsky el haber prolongado la enseñanza de Keynes al análisis de los ciclos lanzados por la expansión del crédito y, de ahí, la posibilidad de crisis mayores en el seno de un capitalismo dominado por grandes empresas que juegan con todas las facilidades de las finanzas. ¿Acaso no fue también él quien hizo inteligibles las estrategias Ponzi, de las cuales los escándalos de 2008 y 2009 muestran la generalidad en los periodos de especulación desenfrenada?

Knut Wicksell es uno de los primeros en haber mostrado las razones por las que la moneda no es neutral; puesto que, asociada al crédito, ésta contribuye a determinar el proceso de formación del capital. De esta manera, las fases de impulso pueden derivar del mantenimiento duradero de tasas de interés más 
débiles que la tasa de rendimiento del capital. No se trata necesariamente del resultado de un error manifiesto de los banqueros centrales, como lo señalan numerosos economistas en contra de Alan Greenspan... ipero una vez que ya estalló la crisis de 2008! En efecto, el imperativo de apoyar a los bancos al momento de salir de una crisis financiera -en este caso, la de la burbuja Internet- puede entrar en contradicción con la optimización del sendero del crecimiento macroeconómico. Finalmente, es demasiado fácil declarar que una autoridad pública no puede detectar una burbuja financiera: el modelo de Von Neumann precisamente permite evaluar el rendimiento real del capital... mucho más inerte de lo que una comunidad financiera impaciente y adepta al valor accionario lo desearía.

Joseph Schumpeter posee el gran mérito de vincular dos de las grandes características de la dinámica de las economías capitalistas: el desarrollo incesante del crédito y las innovaciones, tanto tecnológicas como organizacionales. Por ello, las economías nunca se encuentran en equilibrio walrasiano, ya que se caracterizan por la alternancia de fases de expansión y luego de ajuste por recesiones o depresiones. Basta con extender el análisis a las innovaciones financieras que hicieron época (por ejemplo, la titulización), para obtener una caracterización tanto de las novedades como de la falta de variaciones en el movimiento económico suscitado por la multiplicación de innovaciones financieras consecutivas a su desreglamentación.

Irving Fisher propone a los partidarios de la teoría estándar abandonar la hipótesis de una estabilidad estructural de los procesos de ajuste y reconocer que, en los periodos de crisis, la carrera hacia la liquidez puede ser uno de los factores que transforme una simple recesión en una crisis mayor. Su modelo, que se aplicaba a las relaciones entre crédito y deflación de bienes, se extiende sin dificultad al periodo contemporáneo: basta con tomar en cuenta las relaciones cruzadas entre mercado inmobiliario, crédito y formación de precios de los activos financieros. A partir de esto, la brutalidad y la amplitud de la contracción de la actividad económica en Estados Unidos, especialmente desde septiembre de 2008, encontraron una explicación simple.

Por último, Frank Knight. Él habría merecido convertirse en el tótem de los financieros. ¿Acaso no fue él quien justificó que no existieran ganancias sin la toma de riesgos? Por consiguiente, resultó tentador inventar toda una serie de nuevos productos financieros, inicialmente concebidos para cubrir riesgos y rendir ganancias sustanciales, pero que luego se comprobó desencadenaban una carrera desenfrenada por las ganancias, mediante la multiplicación de riesgos creados de la nada por las propias finanzas. La brutal desvalorización de los acti- 
vos correspondientes nos recuerda que no se trataba de otra cosa sino de anticipaciones de un reparto de ganancias engendradas en la esfera de la economía real. El paso brutal del riesgo a la incertidumbre sistémica explica la parálisis de los actores y la congelación de la actividad financiera... así como la dificultad de las autoridades públicas para imaginar estrategias creíbles de salida de la crisis, debido a lo complejas que son las interdependencias creadas por las innovaciones financieras y las incertidumbres que de ellas derivan.

Lo anterior corresponde al componente hayekiano de la crisis en la línea de su artículo sobre la difusión del conocimiento en economía (Hayek, 1945). Para haber disimulado intencionalmente los riesgos y falseado la integralidad del sistema de los precios de los activos, las propias finanzas generaron la crisis de su institución de base: el mercado como diseminador de la información pertinente.

De esta manera, si los teóricos de las finanzas y los macroeconomistas aceptan voltear hacia la historia de las teorías económicas, muy particularmente hacia aquellas que pusieron en primer plano el origen y la dinámica de las crisis, estarían menos desprovistos de lo que están ahora, cada vez que se enfrentan a ciertos acontecimientos que no tienen cabida en sus elegantes e impresionantes construcciones... que desgraciadamente son incorrectas. Finalmente, última ironía: ¿acaso la teoría estándar no quedó atrapada en un callejón sin salida debido a su referencia al equilibrio walrasiano, a las anticipaciones racionales y a la búsqueda permanente de lo óptimo? ¿Acaso no convendría mejor buscar por el lado de la teoría de los precios, como sistema de información en un universo imperfecto y poco conocido por los actores mismos, el mejor análisis -y la justificación- de una economía de mercado? ¿Acaso Hayek se habría convertido en una alternativa a la Escuela de Chicago?

\section{REFERENCIAS BIBLIOGRÁFICAS}

Aglietta Michel (1978), Régulation et crises du capitalisme, París. Calmann Levy. y André Orléan (comps.) (1998), La monnaie souveraine, París, Odile Jacob.

y - (2002), La monnaie entre violence et confiance, París, Éditions Odile Jacob.

Akerlof George A., y Robert J. Shiller (2009), Animal Spirits: How Human Psychology Drives the Economy and Why it Matters for Global Capitalism, Nueva Jersey, Princeton University Press.

Arrow, Kenneth, y Gérard Debreu (1954), "Existence of an equilibrium for a competitive economy", Econometrica, 22, pp. 522-552. 
Artus, Patrick (2009a), "Le problème essentiel pour la régulation financière et pour le système monétaire international: la finance procyclique", Flash Économie, núm. 155, Vol. 3, París, Natixis, abril.

- (2009b), "Il sera difficile de passer à une finance contracyclique", Flash Economie, núm. 310, Vol. 6, París, Natixis, julio.

Black, Fisher, y Myron Sholes (1973), “The Pricing of Options and Corporate Liabilities”, Journal of Political Economy, Vol. 81, pp. 637-654.

Bouchaud, Jean-Philippe (2009), "Intervention dans le cadre de l'émission 'Peut-on prévoir les crises financières?, séance publique' ", France Culture, núm. 16, enero.

Boyer, Robert, y Benjamin Coriat (1985), "Marx, la technique et la dynamique longue de l'accumulation", en Marx en Perpective, Bernard Chavance Ed., Éditions de l' EHESS, junio, pp. 419-457.

— (1986), La Théorie de la régulation: Une analyse critique, París, La Découverte, Agalma.

e Yves Saillard (comps.) (1995), Théorie de la régulation. L'état des savoirs, La Découverte, París, nueva edición aumentada y actualizada (prefacio y postfacio) (2002).

- (2010), Les capitalismes face à la financiarisation et sa crise, París, Albin Michel, en prensa.

Calomiris, Charles (2009), “A recipe for ratings reform”, The Economists'Voice, www. bepress.com, noviembre.

Cont, Rama (2009), "Risques financiers: quelle modélisation mathématique?", Pour la Science, núm. 375, enero, p. 25.

Crotty James, y Gerald Epstein (2008), “The Costs and Contradictions of theLender-ofLast Resort Function in Contemporary Capitalism: The Sub-Prime Crisis of 2007-2008”, Documento de Trabajo, Political Economy Research Institute (PERI), University of Massachusetts, Amherst, 2-3 de mayo.

Debreu, Gérard (1954), Théorie de la valeur, París, Dunod.

Demyanyk, Yuliya, y Otto van Hemert (2008), "Understanding the Subprime Mortgage Crisis”, Banco de la Reserva Federal de Saint Louis, 19 de agosto, http://ssrn. com/abstract $=1020396$

Eichengreen, Barry (2003), "Les crises récentes en Turquie et en Argentine sont-elles les dernières d'une espèce en voie de disparition?", Revue d'Économie Financière, núm. 70, enero, pp. 51-64.

Fisher, Irwin (1933), "Une théorie de la déflation par la dette”, traducción francesa y reedición en Revue Française d'Economie, Vol. III, núm. 3, verano. 
Garber, Peter M. (2000), Famous First Bubbles: The Fundamental of Early Mania, Cambridge, MIT Press.

Hayek, Friedrich (1945), "The Use of Knowledge in Society", American Economic Review, Vol. XXXV, núm. 4, septiembrer, pp. 519-30.

Hollingsworth, Rogers, y Boyer Robert (comps.) (1997), Contemporary Capitalism: The Embeddedness of Institutions, Cambridge University Press, Cambridge.

Kaldor, Nicholas (1939), "Spéculation et stabilité macroéconomique”, Revue Française d'Economie, Vol. 2, núm. 2-3, pp. 115-164.

- (1966), Causes of the Slow Rate of Growth of the United Kingdom, Cambridge Cambridge, University Press.

Kessler Oliver (2009), "Interrogating the Current Financial Crisis", International Political Sociology, Forum Contribution, Vol. 3, núm. 4, pp. 449-468.

Keynes John-Maynard (1930), Treatise on Money, dos volúmenes, Londres, Mac Millan. (1936), The General Theory of Employment, Interest and Money, Londres, Mac Millan. Existe versión en español: Teoría general de la ocupación, el interés y el dinero, México, Fondo de Cultura Económica, 2003.

Kindleberger Charles P. (1978), Manias, Panics and Crashes, Nueva York, Basics Books. (1994), Histoire mondiale de la spéculation financière, París, Éditions PAU.

Knight, Frank Hynemann (1921), Risk, Uncertainty and Profit, Harper \& Row, reedición 1965.

Krugman, Paul (2009), "How did Economists Get It So Wrong?”, The New York Times, 2 de septiembre.

Lipietz, Alain (1983), Le monde enchanté. De la valeur à l'envol inflationniste, París, La Découverte.

Markowitz, Harry (1952) "Portfolio Selection", The Journal of Finance, Vol. 6, núm. 1, pp. 77-91.

Marx, Karl (1867), Le capital, reedición, Folio Essais, París, 2008. Existe version en español: El capital, México, Siglo XXI, 1981.

— (2009), Les crises du capitalisme, París, Demopolis.

Minsky, Hyman (1975), John-Maynard Keynes, Nueva York, Columbia University Press.

_ (1982 a), Can it Happen Again? Essays on Instability and Finance.

_ (1982 b), "The Financial Instability Hypothesis: Capitalism Processes and the Behavior of the Economy", en Kindleberger Charles, y Jean-Pierre Laffargue (comps.), Financial Instability, París, Dunod.

Orléan, André (2009), De l'euphorie à la panique: Penser la crise financière, Opuscule CEPREMAP, Edition de l'ENS, París. 
Perkins, Anthony B., y Michael C. Perkins (1999), The Internet Bubble, Nueva York, Harper Business.

Plender, John (2009), "How to Tame the Animal Spirits", Financial Times, 30 de septiembre, p. 7.

Plihon, Dominique (comp.) (2002), Rentabilité et risque dans le nouveau régime de croissance, Rapport du Groupe du Commissariat Général du Plan, París, La Documentation Française, octubre.

Reinhart, Carmen M., y Kenneth S. Rogoff (2009), This Time is Different. Eight Centuries of Financial Folly, Princeton, Princeton University Press.

Schumpeter, Joseph (1911), Théorie de l'évolution économique. Recherche sur le profit, le crédit, l'intérêt et le cycle de la conjoncture, traducción francesa (1983), París, Dalloz.

Shiller, Robert J. (2000), Irrational Exuberance, Princeton, N. J., Princeton University Press.

Shleifer, Andrei (2002), Inefficient Markets, Oxford, Oxford University Press.

Touffut, Jean-Philippe (comp.) (2008), Central Banks as Economic Institutions, Edward Elgar, Cheltenham, Gran Bretaña.

Von Neumann, John (1945), “A Model of General Economic Equilibrium”, Review of Economic Studies, Vol. 13.

Wicksell, Knut (1898), Interest and Price, traducción inglesa (1936).

Wolf, Martin (2009), “A présent nous sommes tous des keynésiens", Financial Time, 6 enero, sección Economía, p. IV. 